\title{
Design of new keto-coumarin based photoinitiator for Free Radical Photopolymerization: Towards 3D printing and photocomposites applications
}

\author{
Mahmoud Rahal ${ }^{1,2,3}$, Bernadette Graff ${ }^{1,2}$, Fabrice Morlet-Savary ${ }^{1,2}$, Joumana Toufaily \\ ${ }^{3}$, Tayssir Hamieh ${ }^{3,4}$, Frédéric Dumur ${ }^{5^{*}}$ and Jacques Lalevée ${ }^{1,2 *}$ \\ ${ }^{1}$ Université de Haute-Alsace, CNRS, IS2M UMR 7361, F-68100 Mulhouse, France. mahmoud- \\ rahal@outlook.com (M.R); bernadette.graff@uha.fr r (B.G); jacques.lalevee@uha.fr (J.L.)
}

${ }^{2}$ Université de Strasbourg, Strasbourg, France

${ }^{3}$ Laboratory of Materials, Catalysis, Environment and Analytical Methods (MCEMA) and LEADDER Laboratory, Faculty of Sciences, Doctoral School of Sciences and Technology (EDST), Lebanese University, Beirut 6573-14, Lebanon.tayssir.hamieh@ul.edu.lb (T.H), Joumana.toufaily@ul.edu.lb (J.T)

4 SATIE-IFSTTAR, Université Gustave Eiffel, Campus de Marne-La-Vallée, 25, allée des Marronniers, F-78000 Versailles, France.tayssir.hamieh@ul.edu.lb (T.H)

${ }^{5}$ Aix Marseille Univ, CNRS, ICR UMR 7273, F-13397 Marseille, France; frederic.dumur@univ$\underline{\text { amu.fr }}$

Correspondence: jacques.lalevee@uha.fr (J. L)

\begin{abstract}
In this article, ten organic dyes based on keto-coumarin (KC) derivatives (MeO-Coum1, MeO-Coum10) have been synthesized and characterized as high performance photoinitiators for the Free Radical Photopolymerization (FRP) of acrylates upon visible light exposure using a LED @405nm. The addition of Iodonium salt (Iod), amine [ethyl dimethylaminobenzoate (EDB) or $N$-phenylglycine (NPG)] and Iod/NPG couple in the photocurable resins have been carried out in order to prove their influences on the improvement on the photoinitiating abilities of keto-coumarins. The different dyes showed a very high ability to initiate the FRP by introduction of these additives, using Two or Three-component photoinitiating systems based on $\mathrm{MeO}-\mathrm{Coum} / \mathrm{Iod}$ or amine $(0.1 \%$ or $0.4 \% / 1 \% \mathrm{w} / \mathrm{w})$ or $\mathrm{MeO}-\mathrm{Coum} / \mathrm{Iod} / \mathrm{NPG}(0.1 \%$ or $0.4 \% / 1 \% / 1 \% \mathrm{w} / \mathrm{w} / \mathrm{w})$ respectively. In fact, these photoinitiators have been tested in different applications. For example: in direct laser write to generate 3D patterns using a laser diode @ 405nm, or for the photocomposite synthesis based on glass fibers. To characterize the initiation ability and to explain the reaction mechanisms in the photoinitiation step, several techniques have been used, such as UV-visible absorption spectroscopy and steady state
\end{abstract}


photolysis, fluorescence emission, RT-FTIR, cyclic voltammetry and Electron Spin Resonance (ESR) spectroscopy.

\section{Introduction}

The search for new synthetic strategies that can give access to polymer materials while consuming less energy, less costly, with a fast monomer conversion and with a lower environmental impact, is one of the most worrying challenges today. For this, the production of polymers by photochemical means is more and more used at the academic and industrial levels given their advantages compared to the thermal processes [1-5]. One of these chemical processes used is the Free Radical photopolymerization (FRP) or the Cationic photopolymerization (CP), which consists in the transformation of a liquid resin to a solid material in the presence of a photoinitiating system. Depending on the morphology, the nature as well as their mechanical, chemical and physical properties, these polymers will be used in different sectors of our daily life [6-11]. Thus, the most important step in this process is the initiation, where a photosensitive molecule absorbs light and will thus be able to generate reactive species (radicals or cations) able to produce photopolymerization process. Considering their harmfulness, their high energy consumption as well as the danger for the operator, the use of a UV irradiation source can be limited and thus replaced by the visible source using light-emitting diodes (LED) which are safer, compact, lightweight and with a long lifetime. These equipments give also a greater light penetration in thick samples, and these light sources can also be more monochromatic irradiation sources [12-18]. So, the challenge remains to develop new molecules photosensitive to visible light. In fact, a rather limited number of organic molecules are capable to absorb in the visible region. Hence, the use of Keto-coumarins (KCs) as photoinitiators of photopolymerization is justified by the fact that these compounds are characterized by a very high visible light absorption ability (very high molar extinction coefficient), high triplet state lifetime, a rather low singlet-triplet energy gap. This family of dyes has already been tested as photoinitiating systems for Free Radical Photopolymerization and Cationic Photopolymerization. However, previous works were mostly devoted to 3-phenyl- $2 H$-chromen-2-ones and 3-benzoyl- $2 H$-chromen-2-ones that are highly polyaromatic structures. Conversely, reduction of the aromaticity on methyl 2-oxo- $2 \mathrm{H}-$ chromene-3-carboxylate derivatives can be greatly beneficial for the solubility of the photosensitizers in resins, especially in acrylic resins. Indeed, hydrogen bonds can form between the monomer and the carbonyl and carboxyl groups of methyl 2-oxo-2H-chromene- 
3-carboxylate derivatives, improving its solubility. These products are also good fluorophores [19].

In our work, new keto-coumarin derivatives (Ester functions bonded at the 3-position of the coumarin scaffold - noted $\mathrm{MeO}-\mathrm{Coum}$ in Scheme 1) characterized by a strong visible (and near UV) light-absorbing ability with the molar extinction coefficient of $\sim 16000 \mathrm{M}^{-1} \mathrm{~cm}^{-1}$ for MeO-Coum9 for example, have been tested in two and three-component photoinitiating systems based on MeO-Coum/Iod or amine (EDB or NPG) $(0.1 \% / 1 \%$ w/w) and MeOCoum/Iod/NPG $(0.1 \% / 1 \% / 1 \% \mathrm{w} / \mathrm{w} / \mathrm{w})$ for the FRP of acrylates in thick and thin samples under visible irradiation using a LED @ 405nm. These organic compounds showed a very high initiation ability so that high performances (Final conversions and polymerization rates) could be obtained. As a result of this, the dyes have been tested in laser write experiments as well as in the synthesis of photocomposites using glass fibers for reinforcement purposes. Finally, absorption and emission properties, photochemical properties as well as the redox properties, ability of MeO-Coum to initiate the FRP are directly affected by the impact of these different substituents on the KC scaffold.<smiles>COC(=O)c1cc2ccccc2oc1=O</smiles>

MeO-Coum 1<smiles>COC(=O)c1cc2cccc(OC)c2oc1=O</smiles>

MeO-Coum 5<smiles>COC(=O)c1cc2cc(C)ccc2oc1=O</smiles>

MeO-Coum 2<smiles>CCOc1cccc2cc(C(=O)OC)c(=O)oc12</smiles>

MeO-Coum 6<smiles>COC(=O)c1cc2ccc(O)cc2oc1=O</smiles>

MeO-Coum 3<smiles>COC(=O)c1cc2cc([N+](=O)[O-])ccc2oc1=O</smiles>

MeO-Coum 7<smiles>COC(=O)c1cc2ccc(OC)cc2oc1=O</smiles>

MeO-Coum 4<smiles>COC(=O)c1cc2c(ccc3ccccc32)oc1=O</smiles>

MeO-Coum 8<smiles>CCN(CC)c1ccc2cc(C(=O)OC)c(=O)oc2c1</smiles>

MeO-Coum 9

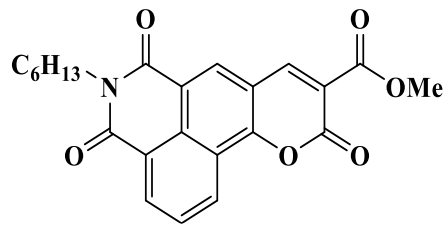

MeO-Coum 10

Scheme 1: Chemical structures of the KCs used in this work.

\section{Experimental part}




\subsection{Synthesis of MeO-Coum derivatives}

All reagents and solvents were purchased from Aldrich or Alfa Aesar and used as received without further purification. Mass spectroscopy was performed by the Spectropole of AixMarseille University. ESI mass spectral analyses were recorded with a 3200 QTRAP (Applied Biosystems SCIEX) mass spectrometer. The HRMS mass spectral analysis was performed with a QStar Elite (Applied Biosystems SCIEX) mass spectrometer. Elemental analyses were recorded with a Thermo Finnigan EA 1112 elemental analysis apparatus driven by the Eager 300 software. ${ }^{1} \mathrm{H}$ and ${ }^{13} \mathrm{C}$ NMR spectra were determined at room temperature in $5 \mathrm{~mm}$ o.d. tubes on a Bruker Avance 400 spectrometer of the Spectropole: ${ }^{1} \mathrm{H}(400 \mathrm{MHz})$ and ${ }^{13} \mathrm{C}(100$ $\mathrm{MHz}$ ). The ${ }^{1} \mathrm{H}$ chemical shifts were referenced to the solvent peaks DMSO (2.49 ppm), $\mathrm{CDCl}_{3}(7.26 \mathrm{ppm})$ and the ${ }^{13} \mathrm{C}$ chemical shifts were referenced to the solvent peak DMSO (49.5 ppm), $\mathrm{CDCl}_{3}(77.0 \mathrm{ppm})$. All photoinitiators were prepared with analytical purity up to accepted standards for new organic compounds (>98\%) which was checked by high field NMR analysis.

\subsubsection{Synthesis of methyl 2-oxo-2H-chromene-3-carboxylate (MeO-Coum1)}

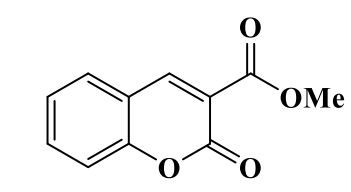

Chemical Formula: $\mathrm{C}_{11} \mathrm{H}_{8} \mathrm{O}_{4}$

Molecular Weight: 204.1810

Salicyldehyde (2 mL, $18.6 \mathrm{mmol})$ and dimethyl malonate $(2.18 \mathrm{~mL}, 19 \mathrm{mmol})$ were suspended in methanol $(50 \mathrm{~mL})$ and a few drops of piperidine were added. The solution was refluxed overnight. After cooling, a precipitate formed. It was filtered off, washed several times with ethanol and dried under vacuum. ${ }^{1} \mathrm{H}$ NMR (300 MHz, $\left.\mathrm{CDCl}_{3}\right) \delta 8.56(\mathrm{~s}, 1 \mathrm{H}), 7.69$ -7.59 (m, 2H), 7.35 (ddd, $J=11.6,6.3,0.7 \mathrm{~Hz}, 2 \mathrm{H}), 3.96$ (s, 3H); HRMS (ESI MS) m/z: theor: 205.0495 found: $205.0492\left([\mathrm{M}+\mathrm{H}]^{+}\right)$. Analyses were consistent with those previously reported in the literature [20].

\subsubsection{Synthesis of methyl 6-methyl-2-oxo-2H-chromene-3-carboxylate (MeO-Coum2)}<smiles>COC(=O)c1cc2cc(C)ccc2oc1=O</smiles> 
5-Methyl-2-hydroxybenzaldehyde (2.53 g, $18.6 \mathrm{mmol}, \mathrm{M}=136.15 \mathrm{~g} / \mathrm{mol})$ and dimethyl malonate $(2.18 \mathrm{~mL}, 19 \mathrm{mmol})$ were suspended in methanol $(50 \mathrm{~mL})$ and a few drops of piperidine were added. The solution was refluxed overnight. Upon cooling, a precipitate formed. It was filtered off, washed several times with methanol and dried under vacuum. ${ }^{1} \mathrm{H}$ NMR (300 MHz, $\left.\mathrm{CDCl}_{3}\right) \delta 8.50(\mathrm{~s}, 1 \mathrm{H}), 7.45(\mathrm{dd}, J=8.5,1.7 \mathrm{~Hz}, 1 \mathrm{H}), 7.38(\mathrm{~s}, 1 \mathrm{H}), 7.25(\mathrm{~d}, J$ $=8.4 \mathrm{~Hz}, 1 \mathrm{H}), 3.95(\mathrm{~s}, 3 \mathrm{H}), 2.42$ (s, 3H); HRMS (ESI MS) m/z: theor: 219.0652 found: $219.0651\left([\mathrm{M}+\mathrm{H}]^{+}\right)$. Analyses were consistent with those previously reported in the literature [21].

\subsubsection{Synthesis of methyl 7-hydroxy-2-oxo-2H-chromene-3-carboxylate (MeO-Coum3)}<smiles>COC(=O)c1cc2ccc(O)cc2oc1=O</smiles>

Chemical Formula: $\mathrm{C}_{11} \mathrm{H}_{8} \mathrm{O}_{5}$ Molecular Weight: 220.1800

2,4-dihydroxybenzaldehyde $(2.57 \mathrm{~g}, 18.6 \mathrm{mmol}, \mathrm{M}=138.12 \mathrm{~g} / \mathrm{mol})$ and dimethyl malonate $(2.18 \mathrm{~mL}, 19 \mathrm{mmol})$ were suspended in methanol $(50 \mathrm{~mL})$ and a few drops of piperidine were added. The solution was refluxed overnight. Upon cooling, a precipitate formed. It was filtered off, washed several times with methanol and dried under vacuum. ${ }^{1} \mathrm{H}$ NMR (400 MHz, DMSO) $\delta 8.69(\mathrm{~s}, 1 \mathrm{H}), 7.75(\mathrm{~d}, J=8.6 \mathrm{~Hz}, 1 \mathrm{H}), 6.85(\mathrm{dd}, J=8.6,2.2 \mathrm{~Hz}, 1 \mathrm{H}), 6.73$ (d, $J=2.1 \mathrm{~Hz}, 1 \mathrm{H}), 3.80(\mathrm{~s}, 3 \mathrm{H})$; HRMS (ESI MS) m/z: theor: 221.0444 found: 221.0445 $\left([\mathrm{M}+\mathrm{H}]^{+}\right.$detected). Analyses were consistent with those previously reported in the literature [22].

\subsubsection{Synthesis of methyl 7-methoxy-2-oxo-2H-chromene-3-carboxylate (MeO-Coum4)}

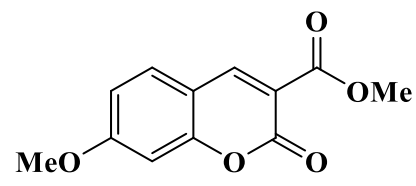

Chemical Formula: $\mathrm{C}_{12} \mathrm{H}_{10} \mathrm{O}_{5}$

Molecular Weight: 234.2070

4-Methoxy-2-hydroxybenzaldehyde (2.83 g, $18.6 \mathrm{mmol}, \mathrm{M}=152.15 \mathrm{~g} / \mathrm{mol})$ and dimethyl malonate $(2.18 \mathrm{~mL}, 19 \mathrm{mmol})$ were suspended in methanol $(50 \mathrm{~mL})$ and a few drops of piperidine were added. The solution was refluxed overnight. Upon cooling, a precipitate formed. It was filtered off, washed several times with methanol and dried under vacuum. ${ }^{1} \mathrm{H}$ 
NMR (300 MHz, $\left.\mathrm{CDCl}_{3}\right) \delta 8.54(\mathrm{~s}, 1 \mathrm{H}), 7.50(\mathrm{~d}, J=8.7 \mathrm{~Hz}, 1 \mathrm{H}), 6.89(\mathrm{dd}, J=8.7,2.4 \mathrm{~Hz}$, 1H), $6.82(\mathrm{~d}, J=2.4 \mathrm{~Hz}, 1 \mathrm{H}), 3.94(\mathrm{~s}, 3 \mathrm{H}), 3.90(\mathrm{~s}, 3 \mathrm{H})$; HRMS (ESI MS) m/z: theor: 235.0601 found: $235.0602\left([\mathrm{M}+\mathrm{H}]^{+}\right)$detected. Analyses were consistent with those previously reported in the literature [23].

\subsubsection{Synthesis of methyl 8-methoxy-2-oxo-2H-chromene-3-carboxylate (MeO-Coum5)}

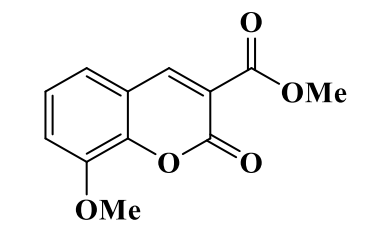

Chemical Formula: $\mathrm{C}_{12} \mathrm{H}_{10} \mathrm{O}_{5}$

Molecular Weight: 234.2070

3-Methoxy-2-hydroxybenzaldehyde (2.83 g, $18.6 \mathrm{mmol}, \mathrm{M}=152.15 \mathrm{~g} / \mathrm{mol})$ and dimethyl malonate $(2.18 \mathrm{~mL}, 19 \mathrm{mmol})$ were suspended in methanol $(50 \mathrm{~mL})$ and a few drops of piperidine were added. The solution was refluxed overnight. Upon cooling, a precipitate formed. It was filtered off, washed several times with methanol and dried under vacuum. ${ }^{1} \mathrm{H}$ NMR (400 MHz, $\left.\mathrm{CDCl}_{3}\right) \delta 8.55(\mathrm{~s}, 1 \mathrm{H}), 7.31$ - 7.27 (m, 1H), 7.22 - 7.20 (m, 1H), 7.19 (dd, $J$ = 2.6, $1.6 \mathrm{~Hz}, 1 \mathrm{H}), 3.99(\mathrm{~s}, 3 \mathrm{H}), 3.97(\mathrm{~s}, 3 \mathrm{H})$; HRMS (ESI MS) m/z: theor: 235.0601 found: $235.0603\left([\mathrm{M}+\mathrm{H}]^{+}\right)$detected. Analyses were consistent with those previously reported in the literature [24].

\subsubsection{Synthesis of methyl 8-ethoxy-2-oxo-2H-chromene-3-carboxylate (MeO-Coum6)}

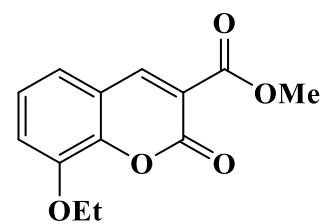

Chemical Formula: $\mathrm{C}_{13} \mathrm{H}_{12} \mathrm{O}_{5}$

Molecular Weight: 248.2340

3-Ethoxy-2-hydroxybenzaldehyde (3.10 g, $18.6 \mathrm{mmol}, \mathrm{M}=166.18 \mathrm{~g} / \mathrm{mol})$ and dimethyl malonate $(2.18 \mathrm{~mL}, 19 \mathrm{mmol})$ were suspended in methanol $(50 \mathrm{~mL})$ and a few drops of piperidine were added. The solution was refluxed overnight. Upon cooling, a precipitate formed. It was filtered off, washed several times with methanol and dried under vacuum. ${ }^{1} \mathrm{H}$ NMR $\left(400 \mathrm{MHz}, \mathrm{CDCl}_{3}\right) \delta 8.52(\mathrm{~s}, 1 \mathrm{H}), 7.23(\mathrm{dd}, J=8.2,7.5 \mathrm{~Hz}, 1 \mathrm{H}), 7.16(\mathrm{ddd}, J=7.4$, 5.0, $1.6 \mathrm{~Hz}, 2 \mathrm{H}), 4.19(\mathrm{q}, J=7.0 \mathrm{~Hz}, 2 \mathrm{H}), 3.94(\mathrm{~s}, 3 \mathrm{H}), 1.50(\mathrm{t}, J=7.0 \mathrm{~Hz}, 3 \mathrm{H}) ;{ }^{13} \mathrm{C} \mathrm{NMR}$ $\left(101 \mathrm{MHz}, \mathrm{CDCl}_{3}\right) \delta 163.83,156.30,149.36,146.49,145.22,124.70,120.61,118.58,118.12$, 
117.22, 65.16, 52.87, 14.69; HRMS (ESI MS) m/z: theor: 249.0757 found: $249.0752\left([\mathrm{M}+\mathrm{H}]^{+}\right.$ detected) [See Reference 20].

\subsubsection{Synthesis of methyl 6-nitro-2-oxo-2H-chromene-3-carboxylate (MeO-Coum7)}<smiles>COC(=O)c1cc2cc([N+](=O)[O-])ccc2oc1=O</smiles>

2-Hydroxy-5-nitrobenzaldehyde (3.11 g, $18.6 \mathrm{mmol}, \mathrm{M}=167.12 \mathrm{~g} / \mathrm{mol})$ and dimethyl malonate $(2.18 \mathrm{~mL}, 19 \mathrm{mmol})$ were suspended in methanol $(50 \mathrm{~mL})$ and a few drops of piperidine were added. The solution was refluxed overnight. Upon cooling, a precipitate formed. It was filtered off, washed several times with ethanol and dried under vacuum. ${ }^{1} \mathrm{H}$ NMR $\left(300 \mathrm{MHz}, \mathrm{CDCl}_{3}\right) \delta 8.61(\mathrm{~s}, 1 \mathrm{H}), 8.56(\mathrm{~d}, J=2.6 \mathrm{~Hz}, 1 \mathrm{H}), 8.50(\mathrm{dd}, J=9.1,2.6 \mathrm{~Hz}$, 1H), $7.51(\mathrm{~d}, J=9.1 \mathrm{~Hz}, 1 \mathrm{H}), 3.99(\mathrm{~d}, J=3.2 \mathrm{~Hz}, 3 \mathrm{H})$; HRMS (ESI MS) m/z: theor: 250.0346 found: $250.0348\left([\mathrm{M}+\mathrm{H}]^{+}\right.$detected $)$. Analyses were consistent with those previously reported in the literature [25].

\subsubsection{Synthesis of methyl 3-oxo-3H-benzo[f]chromene-2-carboxylate (MeO-Coum8)}

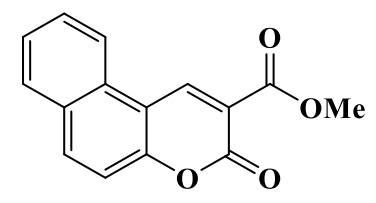

Chemical Formula: $\mathrm{C}_{15} \mathrm{H}_{10} \mathrm{O}_{4}$

Molecular Weight: 254.2410

2-Hydroxy-1-naphthaldehyde (3.20 g, $18.6 \mathrm{mmol}, \mathrm{M}=172.18 \mathrm{~g} / \mathrm{mol})$ and dimethyl malonate $(2.18 \mathrm{~mL}, 19 \mathrm{mmol})$ were suspended in methanol $(50 \mathrm{~mL})$ and a few drops of piperidine were added. The solution was refluxed overnight. Upon cooling, a precipitate formed. It was filtered off, washed several times with methanol and dried under vacuum. ${ }^{1} \mathrm{H}$ NMR (400 $\left.\mathrm{MHz}, \mathrm{CDCl}_{3}\right) \delta 9.31(\mathrm{~s}, 1 \mathrm{H}), 8.30(\mathrm{~d}, J=8.3 \mathrm{~Hz}, 1 \mathrm{H}), 8.08(\mathrm{~d}, J=9.0 \mathrm{~Hz}, 1 \mathrm{H}), 7.91(\mathrm{~d}, J=$ $8.1 \mathrm{~Hz}, 1 \mathrm{H}), 7.74(\mathrm{ddd}, J=8.4,7.0,1.3 \mathrm{~Hz}, 1 \mathrm{H}), 7.60$ (ddd, $J=8.1,7.0,1.0 \mathrm{~Hz}, 1 \mathrm{H}), 7.44$ (d, $J=9.0 \mathrm{~Hz}, 1 \mathrm{H}), 4.00$ (s, 3H); HRMS (ESI MS) m/z: theor: 255.0652 found: 255.0658 $\left([\mathrm{M}+\mathrm{H}]^{+}\right.$detected). Analyses were consistent with those previously reported in the literature [26]. 


\subsubsection{Synthesis of methyl 7-(diethylamino)-2-oxo-2H-chromene-3-carboxylate (MeO-}

\section{Coum9)}

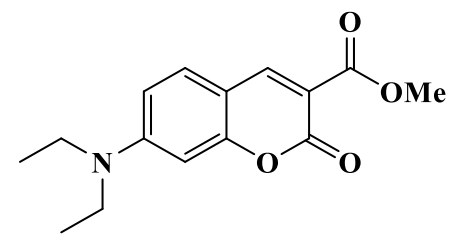

Chemical Formula: $\mathrm{C}_{15} \mathrm{H}_{17} \mathrm{NO}_{4}$

Molecular Weight: 275.3040

4-(Diethylamino)-2-hydroxybenzaldehyde (3.60 g, $18.6 \mathrm{mmol}, \mathrm{M}=193.25 \mathrm{~g} / \mathrm{mol}$ ) and dimethyl malonate $(2.18 \mathrm{~mL}, 19 \mathrm{mmol})$ were suspended in methanol $(50 \mathrm{~mL})$ and a few drops of piperidine were added. The solution was refluxed overnight. After cooling, the solvent was removed under reduced pressure. It was used without any further purification. ${ }^{1} \mathrm{H}$ NMR (400 $\left.\mathrm{MHz}, \mathrm{CDCl}_{3}\right) \delta 8.44(\mathrm{~s}, 1 \mathrm{H}), 7.35(\mathrm{~d}, J=9.0 \mathrm{~Hz}, 1 \mathrm{H}), 6.60(\mathrm{dd}, J=9.0,2.5 \mathrm{~Hz}, 1 \mathrm{H}), 6.45(\mathrm{~d}$, $J=2.4 \mathrm{~Hz}, 1 \mathrm{H}), 3.90(\mathrm{~s}, 3 \mathrm{H}), 3.44(\mathrm{q}, J=7.2 \mathrm{~Hz}, 4 \mathrm{H}), 1.28-1.18(\mathrm{~m}, 7 \mathrm{H}) ;$ HRMS (ESI MS) m/z: theor: 276.1230 found: $276.1225\left([\mathrm{M}+\mathrm{H}]^{+}\right.$detected $)$. Analyses were consistent with those previously reported in the literature [27].

\subsubsection{Synthesis of MeO-Coum10}

\subsubsection{Synthesis of 2-hexyl-6-hydroxy-1H-benzo[de]isoquinoline-1,3(2H)-dione}

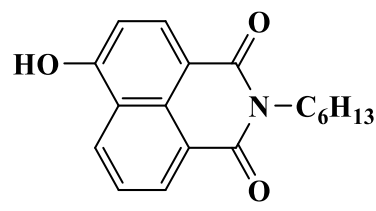

Chemical Formula: $\mathrm{C}_{18} \mathrm{H}_{19} \mathrm{NO}_{3}$

Molecular Weight: 297.3540

2-Hexyl-6-methoxy-1H-benzo[de]isoquinoline-1,3(2H)dione $(5.6 \mathrm{~g}, 18 \mathrm{mmol}, \mathrm{M}=311.38$ $\mathrm{g} / \mathrm{mol})$ was treated with hydriodic acid $(57 \%, 60 \mathrm{~mL})$ at $130^{\circ} \mathrm{C}$ overnight. After cooling, water $(150 \mathrm{~mL})$ was added and the yellow solid was filtered off, washed by water and dried in vacuo. The solid was dissolved in THF. The organic phase was dried over magnesium sulfate and the solvent removed under reduced pressure. Addition of a minimum of DCM followed by the addition of pentane precipitated a yellow solid that was filtered off, washed several times with pentane and dried under vacuum. It was used without any further purification. ${ }^{1} \mathrm{H}$ NMR (300 MHz, DMSO) $\delta 11.86(\mathrm{~s}, 1 \mathrm{H}), 8.55(\mathrm{dd}, J=8.3,1.2 \mathrm{~Hz}, 1 \mathrm{H}), 8.49(\mathrm{dd}, J=7.3,1.2$ $\mathrm{Hz}, 1 \mathrm{H}), 8.37(\mathrm{~d}, J=8.2 \mathrm{~Hz}, 1 \mathrm{H}), 7.78(\mathrm{dd}, J=8.3,7.3 \mathrm{~Hz}, 1 \mathrm{H}), 7.17(\mathrm{~d}, J=8.2 \mathrm{~Hz}, 1 \mathrm{H})$, 
$4.08-3.95(\mathrm{~m}, 2 \mathrm{H}), 1.69-1.53(\mathrm{~m}, 2 \mathrm{H}), 1.41-1.21(\mathrm{~m}, 6 \mathrm{H}), 0.92-0.81(\mathrm{~m}, 3 \mathrm{H})$; HRMS (ESI MS) m/z: theor: 298.1438 found: $298.1439\left([\mathrm{M}+\mathrm{H}]^{+}\right.$detected). Analyses were consistent with those previously reported in the literature [See reference 27].

\subsubsection{Synthesis of 2-hexyl-6-hydroxy-1,3-dioxo-2,3-dihydro-1H-benzo[de]isoquinoline-} 5-carbaldehyde

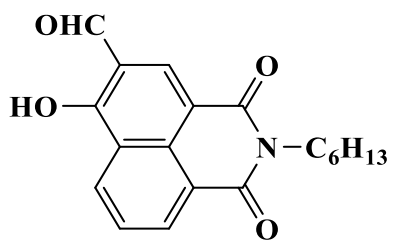

Chemical Formula: $\mathrm{C}_{19} \mathrm{H}_{19} \mathrm{NO}_{4}$

Molecular Weight: 325.3640

2-Hexyl-6-hydroxy-1H-benzo[de]isoquinoline-1,3(2H)-dione (1.90 g, $6.4 \mathrm{mmol}, \mathrm{M}=297.35$ $\mathrm{g} / \mathrm{mol})$ was treated with hexamethylenetetramine $(1.9 \mathrm{~g}, 13.6 \mathrm{mmol})$ in trifluoroacetic acid (40 $\mathrm{mL}$ ) at reflux for $24 \mathrm{~h}$. The reaction mixture was diluted with ice-water and product was extracted into dichloromethane. The organic solution was washed with water several times. The organic phase was dried over magnesium sulfate and the solvent removed under reduced pressure. Addition of DCM followed by pentane precipitated a light-yellow solid that was filtered off, washed several times with pentane and dried under vacuum. ${ }^{1} \mathrm{H}$ NMR $(400 \mathrm{MHz}$, $\left.\mathrm{CDCl}_{3}\right) \delta 13.18(\mathrm{~s}, 1 \mathrm{H}), 10.13(\mathrm{~s}, 1 \mathrm{H}), 8.74(\mathrm{dd}, J=6.3,5.7 \mathrm{~Hz}, 3 \mathrm{H}), 7.84-7.78(\mathrm{~m}, 1 \mathrm{H})$, $4.20-4.14(\mathrm{~m}, 2 \mathrm{H}), 1.73(\mathrm{dt}, J=15.2,7.5 \mathrm{~Hz}, 2 \mathrm{H}), 1.38(\mathrm{ddd}, J=14.6,10.9,5.1 \mathrm{~Hz}, 6 \mathrm{H})$, $0.89(\mathrm{t}, J=7.1 \mathrm{~Hz}, 3 \mathrm{H})$; HRMS (ESI MS) m/z: theor: 326.1387 found: $326.1390\left([\mathrm{M}+\mathrm{H}]^{+}\right.$ detected). Analyses were consistent with those previously reported in the literature [See reference 27].

2.1.10.3 Synthesis of methyl 5-hexyl-4,6,10-trioxo-5,6-dihydro- $4 \mathrm{H}, 10 \mathrm{H}$ benzo[de]pyrano[2,3-g]iso-quinoline-9-carboxylate (MeO-Coum10)

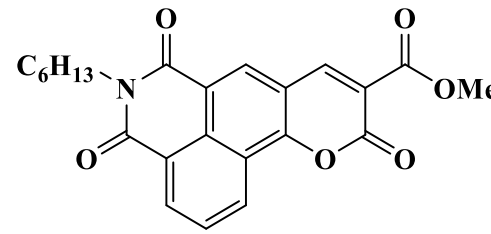

Chemical Formula: $\mathrm{C}_{23} \mathrm{H}_{21} \mathrm{NO}_{6}$

Molecular Weight: 407.4220

2-Hexyl-6-hydroxy-1,3-dioxo-2,3-dihydro-1H-benzo[de]isoquinoline-5-carbaldehyde (6.05 g, $18.6 \mathrm{mmol}, \mathrm{M}=325.36 \mathrm{~g} / \mathrm{mol})$, dimethyl malonate $(2.18 \mathrm{~mL}, 19 \mathrm{mmol})$ were suspended in 
ethanol $(50 \mathrm{~mL})$ and a few drops of piperidine were added. The solution was refluxed overnight. After cooling, the solvent was removed under reduced pressure. The residue was suspended in ethyl acetate and water was added. The aqueous phase was extracted several times with AcOEt. The organic phases were combined, dried over magnesium sulfate and the solvent removed under reduced pressure. ${ }^{1} \mathrm{H}$ NMR $\left(400 \mathrm{MHz}, \mathrm{CDCl}_{3}\right) \delta 8.85(\mathrm{dd}, J=8.4,1.0$ $\mathrm{Hz}, 1 \mathrm{H}), 8.79$ (s, 1H), 8.76 (dd, $J=7.3,1.0 \mathrm{~Hz}, 1 \mathrm{H}), 8.69$ (s, 1H), 7.93 (dd, $J=8.2,7.5 \mathrm{~Hz}$, $1 \mathrm{H}), 4.20-4.14(\mathrm{~m}, 2 \mathrm{H}), 4.01(\mathrm{~s}, 3 \mathrm{H}), 1.73(\mathrm{dt}, J=15.3,7.5 \mathrm{~Hz}, 2 \mathrm{H}), 1.47-1.27(\mathrm{~m}, 6 \mathrm{H})$, $0.89(\mathrm{t}, J=7.1 \mathrm{~Hz}, 3 \mathrm{H})$; HRMS (ESI MS) m/z: theor: 408.1442 found: $408.1444\left([\mathrm{M}+\mathrm{H}]^{+}\right.$ detected). Analyses were consistent with those previously reported in the literature.

The ${ }^{1} \mathrm{H}$ NMR specta of the different Keto-Coumarins are given in the supporting information.

\subsection{Others chemical compounds used in this work}

All the other chemicals (See Scheme 2) were selected with the highest purity available and used as received. Di-tert-butyl-diphenyl iodonium hexafluorophosphate (Iod) and ethyl 4(dimethylamino)benzoate (EDB) were obtained from Lambson Ltd (UK). Trimethylolpropane triacrylate (TMPTA), di(trimethylolpropane) tetraacrylate (TA), $N$-phenylglycine (NPG) were obtained from Allnex or Sigma Aldrich. TMPTA and TA were selected as benchmark monomers for the radical polymerizations.

Additives

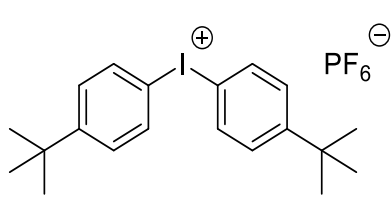

Iod<smiles>O=C(O)CNc1ccccc1</smiles>

NPG<smiles>CCOC(=O)c1ccc(N(C)C)cc1</smiles>

EDB<smiles>Cc1ccc(N(C)C)cc1</smiles>

4-N,N,TMA

\section{Monomers}

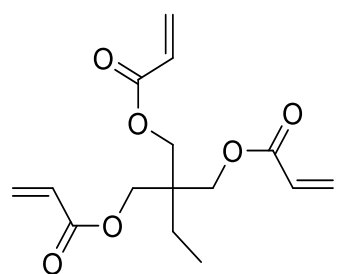

TMPTA<smiles>C=CC(=O)OCC(CC)(COCC(CC)(COC(=O)C=C)COC(=O)C=C)COC(=O)C=C</smiles>

TA

Scheme 2: Other chemical compounds used in this work

\subsection{Irradiation sources}


Light Emitting Diodes (LEDs) were used in this work as safe irradiation sources for different experiments: (1) Steady state photolysis for the different KCs have been carried out using a LED @ $375 \mathrm{~nm}$ with an incident light intensity at the sample surface $\mathrm{I}_{0}=40 \mathrm{~mW} / \mathrm{cm}^{2}$, (2) Photopolymerization experiments have been performed using a LED@ 405nm with $\mathrm{I}_{0}=$ $110 \mathrm{~mW} / \mathrm{cm}^{2}$, (3) Photocomposites were obtained using a LED conveyor @395nm with $\mathrm{I}_{0}=4$ $\mathrm{W} / \mathrm{cm}^{2}$.

\subsection{Free Radical Photopolymerization (FRP) of acrylate functions: Kinetic followed and final conversion (FC) determination by RT-FTIR}

The FRP experiments of acrylate functions for the different Keto-Coumarins have been achieved using two or three-component photoinitiating systems based on MeO-Coum/Iod salt or amine (EDB or NPG) $(0.1 \%$ or $0.4 \% / 1 \%$ w/w) or MeO-Coum/Iod/NPG (or EDB) $(0.1 \%$ or $0.4 \% / 1 \% / 1 \%$ w/w/w) upon visible light irradiation using a LED @ 405nm. The weight percent of the different compounds (Photoinitiators and additives) is calculated from the monomer content.

The photopolymers are obtained by two different treatments: (1) in thick sample (Thickness $=1.4 \mathrm{~mm})$ using a circular mold $(1.4 \mathrm{~mm})$, where the photosensitive resin (Acrylate and EPOX) is deposited, and (2) in thin sample (Thickness $=25 \mu \mathrm{m}$ ), where the photopolymerizable resin is deposited in sandwich between two polypropylene films (to avoid oxygen diffusion). In fact, the kinetics tracking as well as the final reactive function conversions (FC) of different photoinitiating systems are obtained using a JASCO 6600 FTIR spectrometer. The monomer conversions were determined by following the evolution of the $\mathrm{C}=\mathrm{C}$ peak located at $6160 \mathrm{~cm}^{-1}$ and $1630 \mathrm{~cm}^{-1}$ for the Thick and Thin samples respectively.

\subsection{Redox potentials: Free energy change determination}

Oxidation potential and reduction potential for $\mathrm{KCs}\left(\mathrm{E}_{\mathrm{ox}}\right.$ and $\left.\mathrm{E}_{\mathrm{red}}\right)$ were determined by cyclic voltammetry using tetrabutylammonium hexafluorophosphate as the supporting electrolyte (potentials vs. Saturated Calomel Electrode - SCE) in acetonitrile (ACN). The free energy change $\left(\Delta \mathrm{G}_{\mathrm{et}}\right)$ for an electron transfer reaction was calculated from eq.1 [28], where $\mathrm{E}_{\mathrm{ox}}, \mathrm{E}_{\mathrm{red}}, \mathrm{E}^{*}$, and $\mathrm{C}$ represent the oxidation potential of the electron donor, the reduction potential of the electron acceptor, the excited state energy level (obtained from the crossing point of the UV-visible and fluorescence spectra) and the coulombic term for the initially formed ion pair, respectively. Here, $\mathrm{C}$ is neglected as usually done for polar solvents.

$$
\Delta \mathrm{G}_{\mathrm{et}}=\mathrm{E}_{\mathrm{ox}}-\mathrm{E}_{\mathrm{red}}-\mathrm{E}^{*}+\mathrm{C}
$$




\subsection{UV-Visible absorption, photolysis experiments and fluorescence spectroscopy to suggest the chemical mechanism}

A JASCO V730 UV-visible spectrometer was used to study the UV-visible absorption, the molar extinction coefficients and the steady state photolysis experiments of the different Keto-coumarins compounds in acetonitrile (ACN). In the other hand, luminescence properties as well as the fluorescence quenching experiments of the different KCs were investigated using a JASCO FP-6200 spectrofluorimeter. According to the classical Stern-Volmer treatment [29] $\left(\mathrm{I}_{0} / \mathrm{I}=1+\mathrm{kq} \tau_{0}[\mathrm{Iod}]\right.$, where $\mathrm{I}_{0}$ and I stand for the fluorescent intensity of ketocoumarins in the absence and the presence of Iod, respectively; $\tau_{0}$ stands for the lifetime of keto-coumarins in the absence of Iod), the quantum yields of the PI quenched by Iod in ACN could be determined.

\subsection{Electron spin resonance (ESR) spin trapping (ESR-ST)}

Electron spin resonance-spin trapping experiments were performed using an X-band spectrometer (Bruker EMX-plus). The radicals were obtained at room temperature under nitrogen $\left(\mathrm{N}_{2}\right)$ saturated tert-butylbenzene: Dichloromethane (95:5) solutions. N-Tert-butylphenylnitrone $(\mathrm{PBN})$ was used as the spin trap agent in a similar way as described in other works [reference]. ESR spectra simulations were carried out using WINSIM software.

\subsection{Computational Procedure}

Molecular orbital calculations were carried out with the Gaussian 03 suite of programs [30,31]. Electronic absorption spectra for the different compounds were calculated with the time-dependent density functional theory at the MPW1PW91-FC/6-31G* level of theory on the relaxed geometries calculated at the UB3LYP/6-31G* level of theory.

\subsection{Photocomposites synthesis using a LED Near-UV conveyor}

A Dymax-UV conveyor was used to synthesize photocomposites. First of all, the photosensitive resin was deposited on the glass fibers $(50 \% / 50 \% \mathrm{w} / \mathrm{w})$, then the photocomposites were obtained by irradiation of the sample using a LED conveyor @395 nm $\left(4 \mathrm{~W} / \mathrm{cm}^{2}\right)$. The distance between the belt and the LED was fixed at $15 \mathrm{~mm}$, and the belt speed was fixed at $2 \mathrm{~m} / \mathrm{min}$.

\subsection{Direct laser write and 3D printing experiments}


3D patterns were obtained using a computer-controlled diode laser at $405 \mathrm{~nm}$ (spot size $=$ $50 \mu \mathrm{m})$, which were performed under air and analysed by a numerical optical microscope (DSX-HRSU from OLYMPUS Corporation) [32].

\section{Result and discussion}

In this part, we discuss the impact of different substituents, linked to the Keto-Coumarins core, on the absorption properties, photochemical and photophysical properties as well as the FRP efficiency.

\subsection{Investigation of UV-Visible spectra of Keto-Coumarins derivatives}

The UV-visible absorption spectra of the new investigated Keto-Coumarins in acetonitrile $(\mathrm{ACN})$ are presented in Figure 1 (See also Table 1). These compounds are characterized by a very high molar extinction coefficient in both, near-UV and visible range (e.g. MeO-Coum8 $41000 \mathrm{M}^{-1} \cdot \mathrm{cm}^{-1} @ 344 \mathrm{~nm}$ and $3100 \mathrm{M}^{-1} \cdot \mathrm{cm}^{-1} @ 405 \mathrm{~nm}$, and MeO-Coum9 $17500 \mathrm{M}^{-1} \cdot \mathrm{cm}^{-1}$ @416nm and $\left.15851 \mathrm{M}^{-1} \cdot \mathrm{cm}^{-1} @ 405 \mathrm{~nm}\right)$. More specifically, their absorptions are very interesting in the 300-480 nm spectral range, so a good overlap is ensured with the emission spectra of the LEDs used in this work (LED@ $405 \mathrm{~nm}$ for the photopolymerization experiments, $375 \mathrm{~nm}$ for the steady state photolysis experiments and $395 \mathrm{~nm}$ for the photocomposites synthesis).

The absorption properties of the keto-coumarins are directly related to the presence of a donor or acceptor groups linked to the KC scaffold. Remarkably, a bathochromic effect is observed due to the presence of the donor groups on the Keto-Coumarin core which destabilizes the $\pi-\pi^{*}$ transition, while a hypsochromic effect is observed upon introduction of an accepting group which stabilizes the $\pi-\pi^{*}$ transition (in the case of $\mathrm{MeO}-\mathrm{Coum} 7$ which shows a blue-shifted absorption due to the presence of an electron accepting group $\mathrm{NO}_{2}$ ). Therefore, MeO-Coum8, MeO-Coum9 and MeO-Com10 have the most red-shifted absorption spectra due to the presence of the donating groups (Ar, $\mathrm{N}\left(\mathrm{CH}_{2} \mathrm{CH}_{3}\right)_{2}$ and Naphtalimide group respectively). Taking MeO-Com1 as the original structure, the UV-visible absorption spectra of $\mathrm{MeO}-\mathrm{Coum} 2,3$ and 4 are slightly red shifted due to the presence of a weak donor group $\left(\mathrm{CH}_{3}, \mathrm{OH}\right.$ and $\mathrm{OCH}_{3}$ respectively), $\mathrm{MeO}-\mathrm{Coum} 3$ and 4 have high extinction coefficients due to the $n-\pi *$ transition which is not present in MeO-Coum2 (absence of a heteroatom). On the 
other hand, the UV-visible absorption spectra of MeO-Coum5 and 6 show a hypsochromic effect despite the presence of the donor group $\left(\mathrm{OH}\right.$ and $\left.\mathrm{OCH}_{3}\right)$.

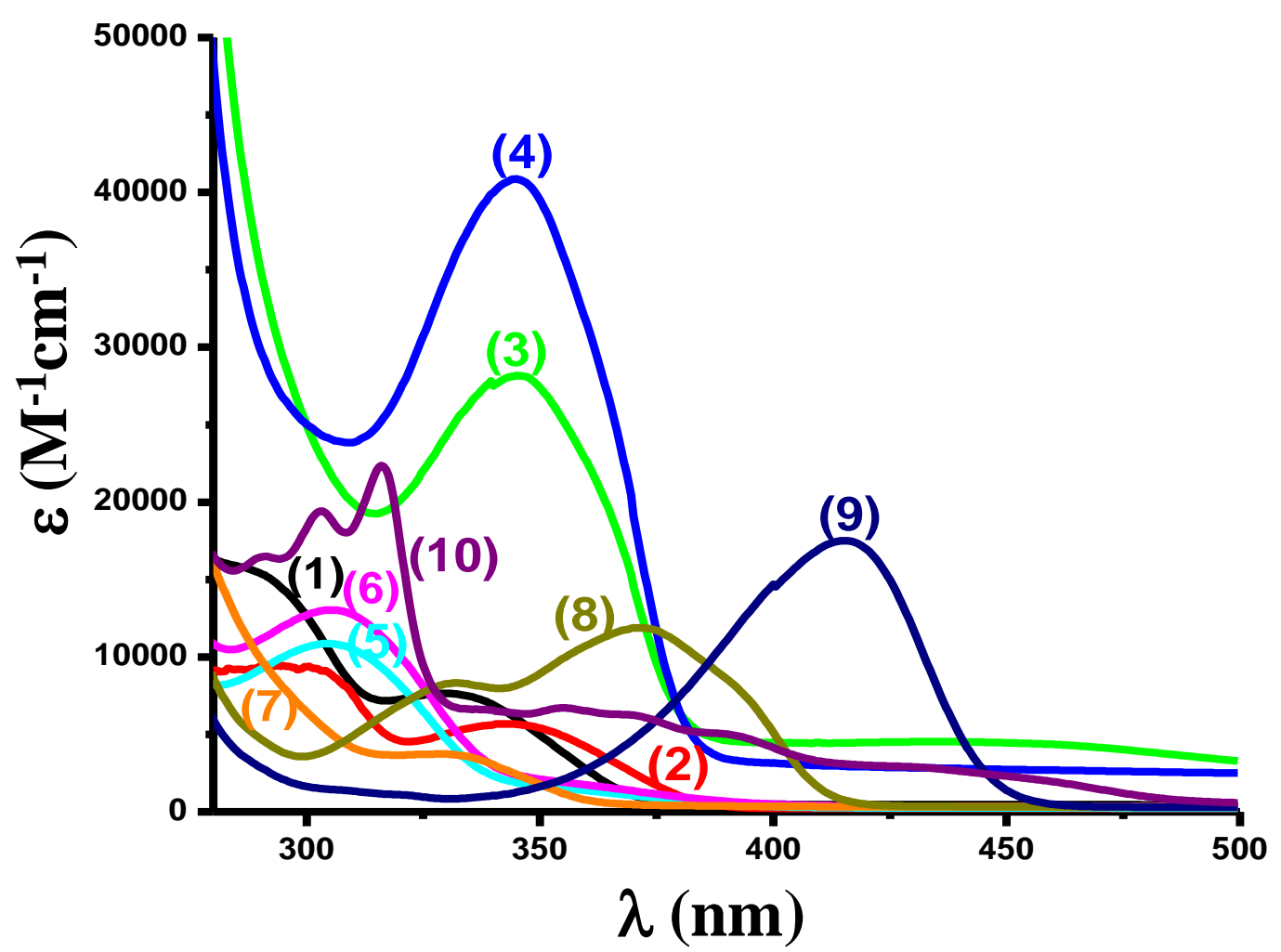

Figure 1: UV-visible absorption spectra of the KCs in ACN: (1) MeO-Coum1, (2) MeO-Coum2, (3) MeO-Coum3, (4) MeO-Coum4, (5) MeO-Coum5, (6) MeO-Coum6, (7) MeO-Coum7, (8) MeOCoum8 and (9) MeO-Coum9 and (10) MeO-Coum10.

Tableau 1: Light absorption properties of Keto-Coumarins at $405 \mathrm{~nm}$ and at $\lambda_{\max }$

\begin{tabular}{|c|c|c|c|}
\hline & $\boldsymbol{\lambda}_{\max (\mathbf{n m})}$ & $\boldsymbol{\varepsilon m a x}\left(\mathbf{M}^{-\mathbf{1}} \mathbf{c m}^{-\mathbf{1}}\right)$ & $\boldsymbol{\varepsilon} \mathbf{4 0 5} \mathbf{n m}\left(\mathbf{M}^{-\mathbf{1}} \mathbf{c m}^{-\mathbf{1}}\right)$ \\
\hline MeO-Coum1 & 330 & 15900 & 480 \\
\hline MeO-Coum2 & 343 & 10000 & 190 \\
\hline MeO-Coum3 & 345 & 28200 & 4440 \\
\hline MeO-Coum4 & 344 & 40900 & 3060 \\
\hline MeO-Coum5 & 304 & 10900 & 300 \\
\hline MeO-Coum6 & 305 & 13000 & 440 \\
\hline MeO-Coum7 & 328 & 3700 & 350 \\
\hline MeO-Coum8 & 372 & 11900 & 3000 \\
\hline MeO-Coum9 & 416 & 17500 & 15800 \\
\hline MeO-Coum10 & 316 & 22400 & 3600 \\
\hline
\end{tabular}


HOMO

LUMO

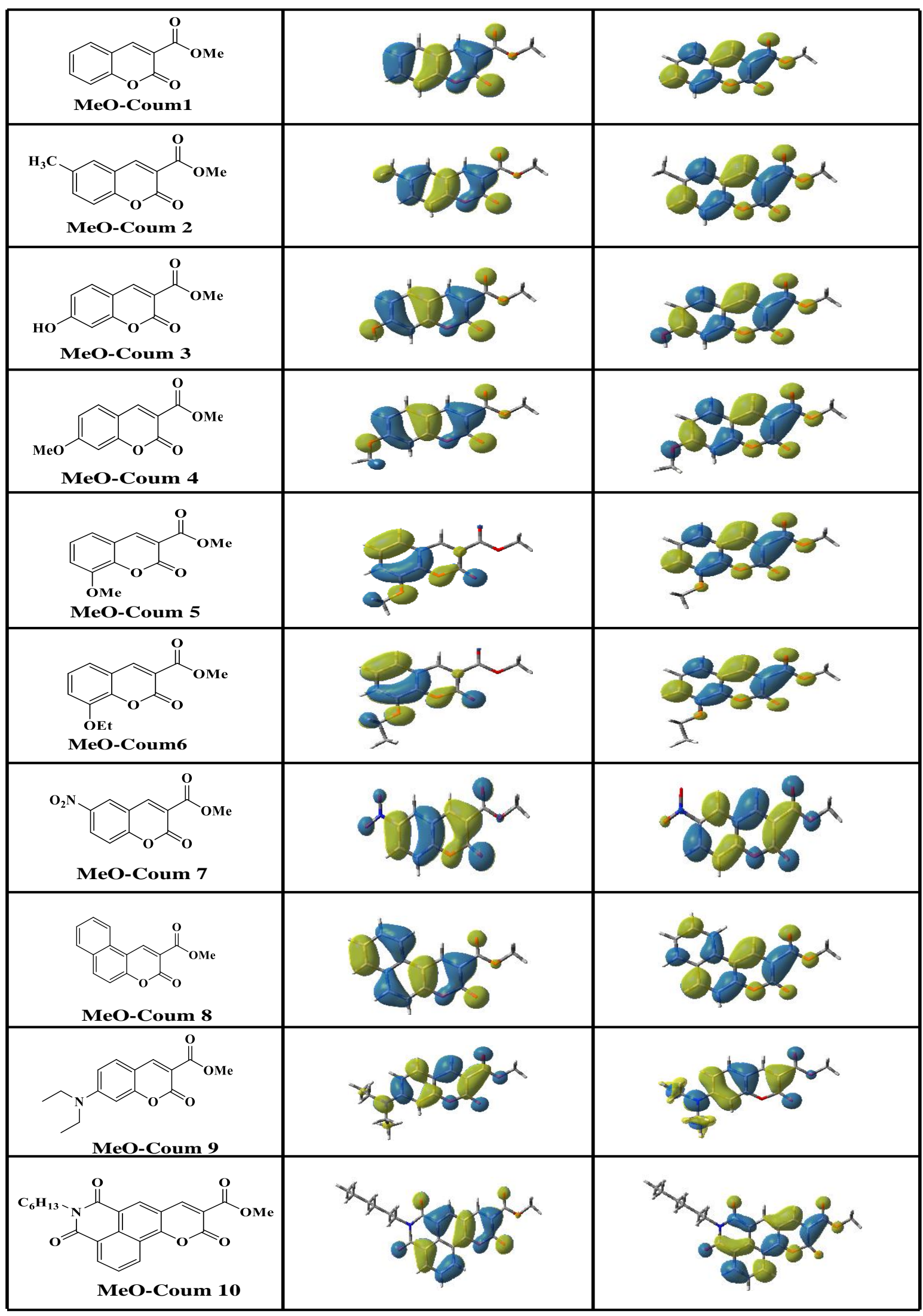

Figure 2: HOMO and LUMO frontier orbitals and their respective calculated UV-Visible absorption spectra for the different investigated compounds at the UB3LYP/6- 31G* level. 


\subsection{Free Radical Photopolymerization (FRP) of acrylate functions of TMPTA and TA}

The FRP using TMPTA or TA as benchmark acrylate monomers have been performed for both thick $(1.4 \mathrm{~mm})$ or thin $(25 \mu \mathrm{m})$ samples using two or three-component photoinitiating systems upon visible light irradiation with a LED @405nm. The polymerization profiles are depicted in Figure 3 (See also Table 2). First of all, Keto-Coumarins alone or additives alone (e.g. Iod, EDB and NPG) cannot initiate the FRP. This result clearly shows the importance of introducing a PI able to absorb a near-UV or visible light, since the additives are not able to absorb near UV or visible light. In fact, MeO-Coum8, 9 and 10 are very effective where they coupled with Iod or NPG $(0.1 \% / 1 \% \mathrm{w} / \mathrm{w})$ using TA (final acrylate function conversion $(\mathrm{FC})=$ $81 \%, 70 \%$ and $61 \%$ respectively with Iod and $86 \%, 83 \%$ and $87 \%$ respectively with NPG), but all other compounds (except MeO-Coum2 and 7) initiates effectively the FRP of acrylate functions in the presence of NPG $(0.4 \% / 1 \%$ w/w) (e.g. FC $=71 \%, 70 \%, 75 \%$ and $74 \%$ for MeO-Coum3,4,5,6). These results clearly show that MeO-Coum8,9 and 10 presents a photooxidation and photo-reduction process, and that MeO-Coum3,4,5,6 show mainly a photoreduction process. In order to improve the performance of FRP, a three-component photoinitiating system PIS was prepared by introduction of NPG into the photosensitive formulation. In fact, a charge transfer complex (CTC) could be obtained by interaction between Iod and NPG. This CTC could weakly initiate the FRP of acrylates (FC $=47 \%$ in TMPTA and 77\% in TA). The performance (Final conversion and rate of polymerization) was improved by addition of Keto-Coumarin into the photocurable resin.

Remarkably, MeO-Coum/Iod/NPG $(0.1 \%$ or $0.4 \% / 1 \% / 1 \% \mathrm{w} / \mathrm{w} / \mathrm{w})$ was more efficiency compared to $\mathrm{MeO}-\mathrm{Coum} / \mathrm{Iod}$ or NPG $(0.1 \%$ or $0.4 \% / 1 \%$ w/w) (e.g. $\mathrm{FC}=86 \%$ for $\mathrm{MeO}$ Coum8/NPG vs. $91 \%$ for MeO-Coum8/Iod/NPG Figure 3B vs. 3C curve 8, $74 \%$ for $\mathrm{MeO}-$ Coum6/NPG vs. 87\% for MeO-Coum6/Iod/NPG Figure 3B vs. 3C curve 6). 

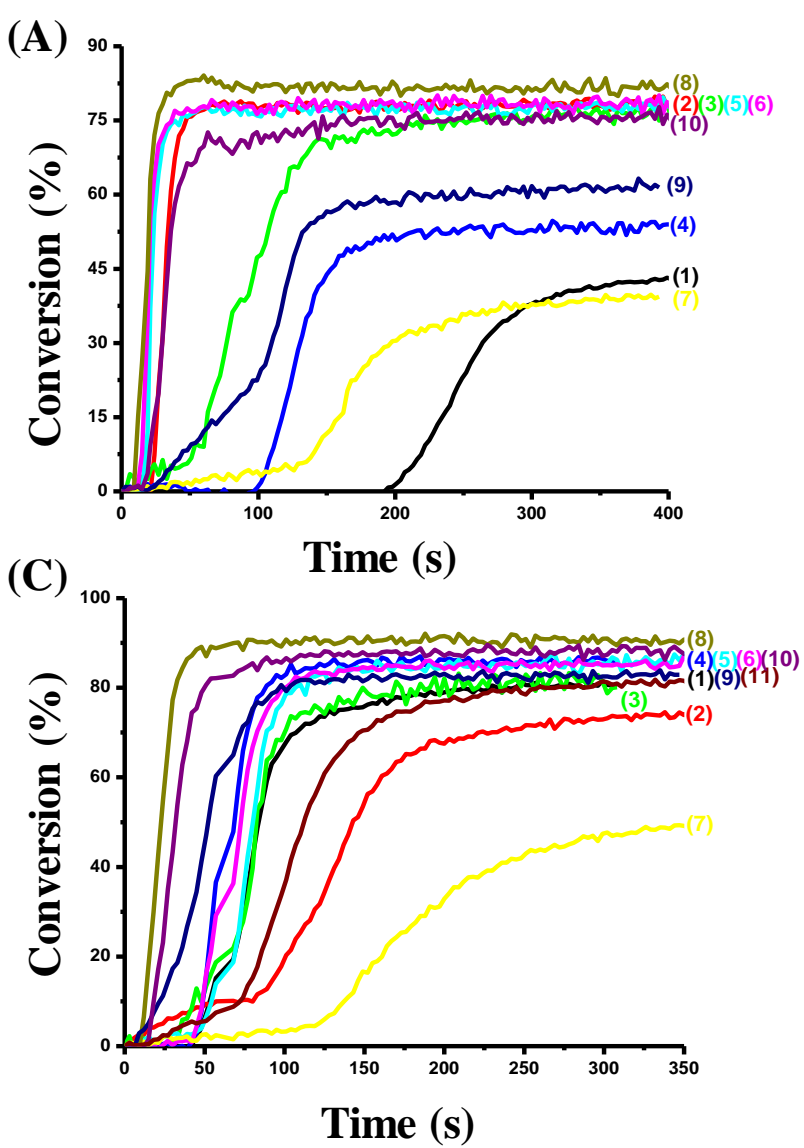
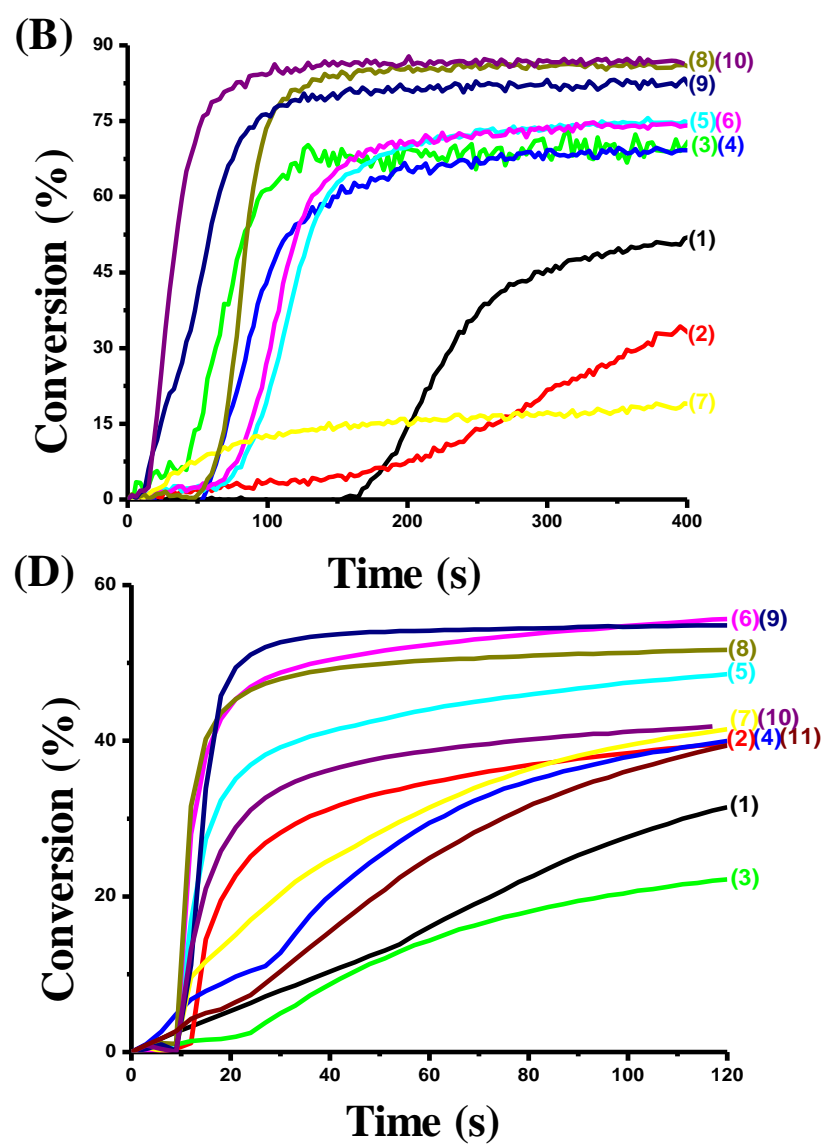

Figure 3: Free Radical photopolymerization profiles of acrylate functions (conversion vs irradiation time) in Thick (A,B and C) and Thin sample (D) upon visible light irradiation using a LED@405nm: $(\mathrm{A}, \mathrm{B})$ using Two component PIS based on MeO-Coum/NPG, (C,D) using Three-component PIS based on $\mathrm{MeO}-\mathrm{Coum} / \mathrm{Iod} / \mathrm{NPG}(0.1 \%$ or $0.4 \% / 1 \% \mathrm{w} / \mathrm{w})$ : (1) MeO-Coum1 (0.4\%), (2) MeO-Coum2 (0.4\%), (3) MeO-Coum3 (0.4\%), (4) MeO-Coum4 (0.4\%), (5) MeO-Coum5 (0.4\%), (6) MeOCoum6 (0.4\%), (7) MeO-Coum 7 (0.4\%), (8) MeO-Coum8 (0.1\%), (9) MeO-Coum9 (0.1\%), (10) MeO-Coum10 (0.1\%) and (11) Iod/NPG $(1 \% / 1 \% \mathrm{w} / \mathrm{w})$. (A,D) in TMPTA and (B,C) in TA. Irradiation starts at $\mathrm{t}=10 \mathrm{~s}$.

Tableau 2: Final reactive function conversions (FC\%) for different monomers and different PISs upon visible light irradiation using a LED @ 405nm (400 s of irradiation and thickness = $1.4 \mathrm{~mm}$ ).

\begin{tabular}{|l|c|c|c|c|c|c|}
\hline \multirow{2}{*}{} & \multicolumn{2}{|c|}{ Two component photoinitiating systems } & \multicolumn{2}{c|}{ Three component photoinitiating systems } \\
\cline { 2 - 7 } & \multicolumn{2}{|c|}{ TMPTA } & \multicolumn{2}{c|}{ TA } & TMPTA & TA \\
\cline { 2 - 7 } & $\mathbf{1 \%}$ Iod & $\mathbf{1 \%}$ NPG & $\mathbf{1 \% \text { Iod }}$ & $\mathbf{1 \% \text { NPG }}$ & $\begin{array}{c}\text { Iod/NPG } \\
(\mathbf{1 \%} / \mathbf{1 \%} \mathbf{w} / \mathbf{w})\end{array}$ & $\begin{array}{c}\text { Iod/NPG } \\
(\mathbf{1 \%} / \mathbf{1 \%} \mathbf{w} / \mathbf{w})\end{array}$ \\
\hline MeO Coum1 & n.p & $36 \%$ & n.p & $52 \%$ & $73 \%$ & $81 \%$ \\
\hline MeO Coum2 & n.p & $39 \%$ & n.p & $34 \%$ & $83 \%$ & $76 \%$ \\
\hline MeO Coum3 & n.p & $41 \%$ & n.p & $71 \%$ & $70 \%$ & $83 \%$ \\
\hline MeO Coum4 & n.p & $18 \%$ & n.p & $70 \%$ & $71 \%$ & $87 \%$ \\
\hline
\end{tabular}




\begin{tabular}{|c|l|l|l|l|l|l|}
\hline MeO Coum5 & $23 \%$ & $52 \%$ & $12 \%$ & $75 \%$ & $84 \%$ & $87 \%$ \\
\hline MeO Coum6 & $18 \%$ & $50 \%$ & $13 \%$ & $74 \%$ & $86 \%$ & $87 \%$ \\
\hline MeO Coum7 & $32 \%$ & $38 \%$ & $10 \%$ & $19 \%$ & $70 \%$ & $52 \%$ \\
\hline MeO Coum8 & $18 \%$ & $51 \%$ & $81 \%$ & $86 \%$ & $86 \%$ & $91 \%$ \\
\hline MeO Coum9 & $34 \%$ & $45 \%$ & $70 \%$ & $83 \%$ & $74 \%$ & $84 \%$ \\
\hline MeO Coum10 & $38 \%$ & $32 \%$ & $65 \%$ & $87 \%$ & $78 \%$ & $89 \%$ \\
\hline
\end{tabular}

${ }^{1}$ n.p : no polymerization

\subsection{Direct laser write and 3D printing using MeO-Coum/Iod/amine system}

A diode laser @405nm was used for the generation of 3D polymers patterns which were characterized by optical microscopy. This experiment was carried out under air and using different PISs based on MeO-Coum/Iod/TMA in TMPTA or TA (See Figure 4). Remarkably, a great thickness could be obtained $(\sim 1900 \mu \mathrm{m})$, with a high spatial resolution (polymerization process is produced in the irradiated area) and very short irradiation times were necessary to generate the 3D patterns. Some 3D printing experiments were also carried out using a low light intensity 3D printer (LCD-based 405 nm 3D Printer Anycubic Photon S) (Figure 4E) showing the high photosensitivity of the proposed systems. 


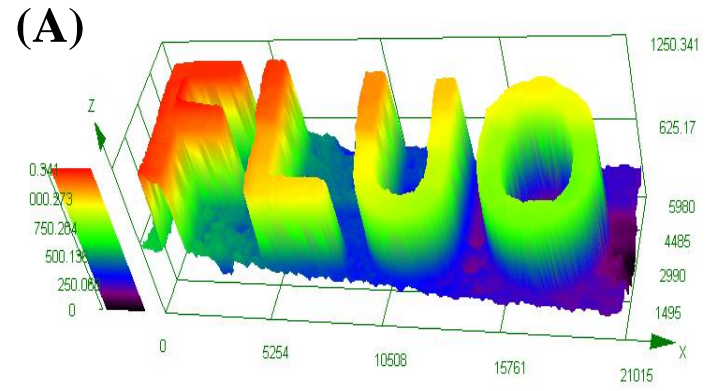

(C)

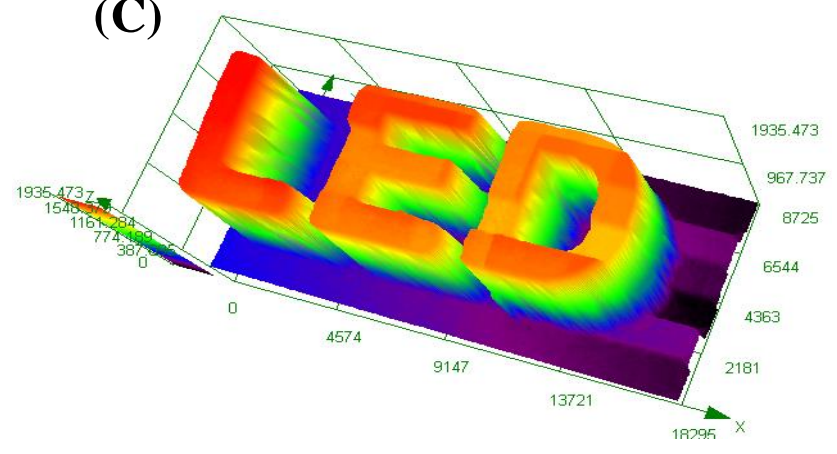

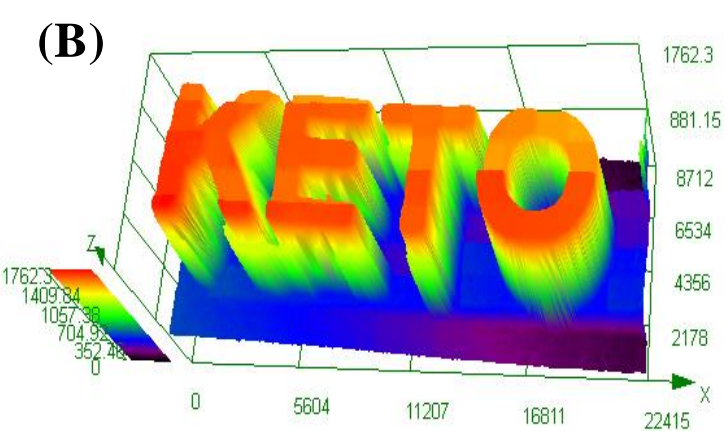

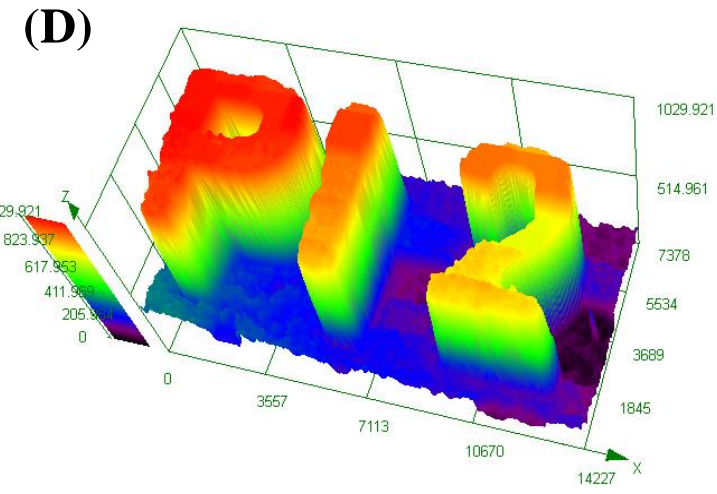

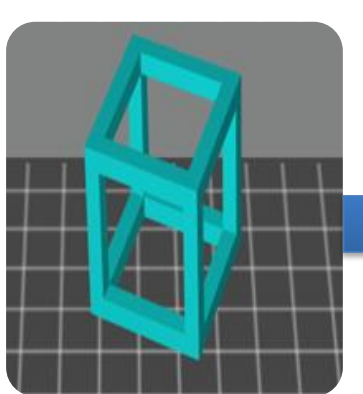

(E)

3D printing

Figure 4: Free Radical Photopolymerization experiments using a laser diode @405nm for the generation of 3D patterns characterized by numerical optical microscopy: (A) MeO-Coum2/Iod/TMA $(0.15 \% / 0.5 \% / 0.175 \% \mathrm{w} / \mathrm{w} / \mathrm{w})$ in TA, (B) MeO-Coum5/Iod/TMA $(0.15 \% / 0.5 \% / 0.23 \% \mathrm{w} / \mathrm{w} / \mathrm{w})$ in TMPTA, (C) MeO-Coum6/Iod/NPG $(0.266 \% / 0.667 \% / 0.667 \mathrm{w} / \mathrm{w} / \mathrm{w})$ in TMPTA, (D) MeOCoum8/Iod/TMA $(0.05 \% / 0.5 \% / 0.18 \% \mathrm{w} / \mathrm{w} / \mathrm{w})$ in TMPTA and (E) 3D printing experiments using MeO-Coum8/Iod/TMPTA $(0.1 \% / 1 \% / 1 \% \mathrm{w} / \mathrm{w} / \mathrm{w})$ in TMPTA.

\subsection{Photopolymerization of acrylate monomer for the access to photocomposite}

In view of their costs/performance ratios, glass fibers are widely used in reinforcement applications in composite preparation. Due to their ability to initiate Free Radical Photopolymerization, some KCs were selected for the synthesis of photocomposites using TMPTA as the organic matrix and glass fibers as reinforcement $(50 \% / 50 \% \mathrm{w} / \mathrm{w})$ upon nearUV light using a LED conveyor @ $395 \mathrm{~nm}\left(4 \mathrm{~W} / \mathrm{cm}^{2}\right)$. The obtained results are depicted in the Figure 5. Firstly, the glass fibers were impregnated by the photosensitive resin, then this sample was irradiated, and a very fast curing was obtained using MeO-Coum/Iod/NPG (0.1\% or $0.4 \% / 1 \% / 1 \% \mathrm{w} / \mathrm{w} / \mathrm{w})$. It is important to note that both the surface and the bottom are tack- 
free after 1 pass only (for MeO-Coum 2,5,6) and 1 pass only at their surfaces and 2 passes on the bottom for MeO-Coum 8,9,10.

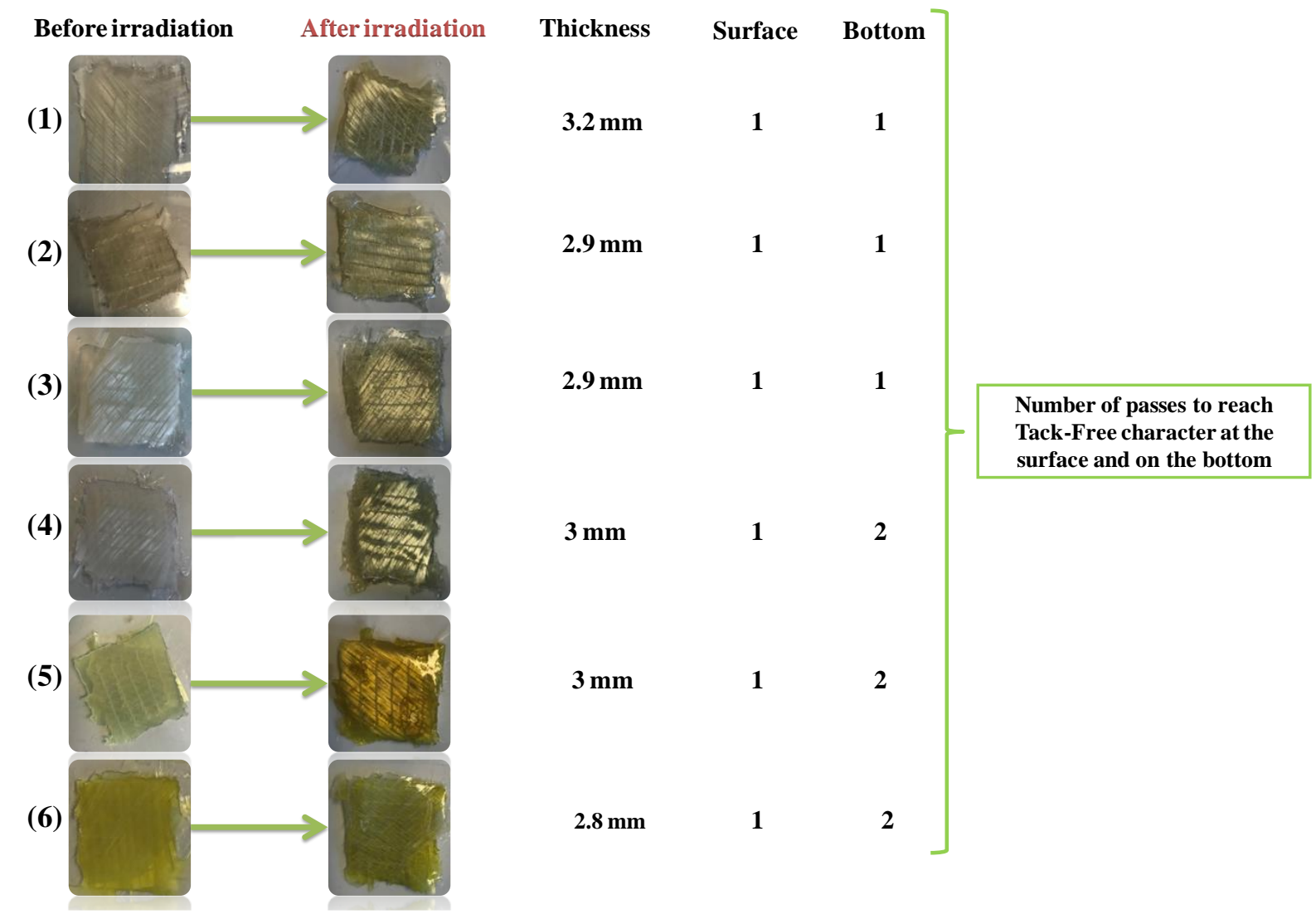

Figure 5: FRP experiments of acrylates (TMPTA) for photocomposites curing using a LED conveyor @ 395nm: (1) MeO-Coum2 /Iod /NPG $(0.4 \% / 1 \% / 1 \% \mathrm{w} / \mathrm{w} / \mathrm{w})$, (2) $\mathrm{MeO}-\mathrm{Coum} 5 / \mathrm{Iod} / \mathrm{NPG}$ (0.4\%/1\%/1\% w/w/w), (3) MeO-Coum6/Iod/NPG (0.4\%/1\%/1\% w/w/w), (4) MeO-Coum8/Iod/NPG $(0.1 \% / 1 \% / 1 \% \quad \mathrm{w} / \mathrm{w} / \mathrm{w}), \quad$ (5) $\quad \mathrm{MeO}-\mathrm{Coum} 9 / \mathrm{Iod} / \mathrm{NPG} \quad(0.1 \% / 1 \% / 1 \% \quad \mathrm{w} / \mathrm{w} / \mathrm{w})$ and (6) $\mathrm{MeO}-$ Coum10/Iod/NPG $(0.1 \% / 1 \% / 1 \% \mathrm{w} / \mathrm{w} / \mathrm{w})$.

\section{Discussion: Photochemical mechanisms}

The photochemical and photophysical properties of Keto-Coumarins in solution will be discussed in this part.

\subsection{Steady state photolysis of Keto-Coumarin derivatives}

Photolysis experiments of the different $\mathrm{KCs}$ in ACN have been carried out using a LED @ $375 \mathrm{~nm}$. One of these compounds (MeO-Coum8) was chosen and presented in Figure 6 to explain the results obtained by FRP. First of all, no photolysis occurs for MeO-Coum8 alone (Figure 6A), but a very fast photolysis of this compound is observed in the presence of Iod $\left(10^{-2} \mathrm{M}\right)$. These results clearly show that MeO-Coum8 is photostable. Decrease of the absorption peak of MeO-Coum8 and the increase in the optical density between $420 \mathrm{~nm}$ and 
$500 \mathrm{~nm}$ show that an interaction between the $\mathrm{KC}$ and Iod occurs. This interaction can be explained by an electron transfer process which generates a radical and a photoproduct when they are irradiated. The consumption percentage obtained by $\mathrm{KC} / \mathrm{Iod}$ photolysis (56\%) is very high compared to that in the presence of $\mathrm{KC}$ alone (no consumption occurs) (Figure 6C curve 1 vs. 2).

(A)

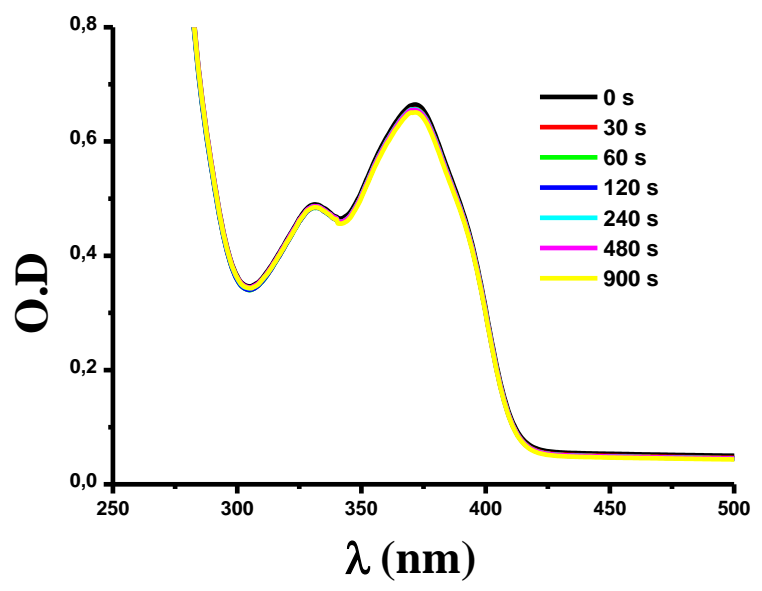

(C)

\section{(B)}

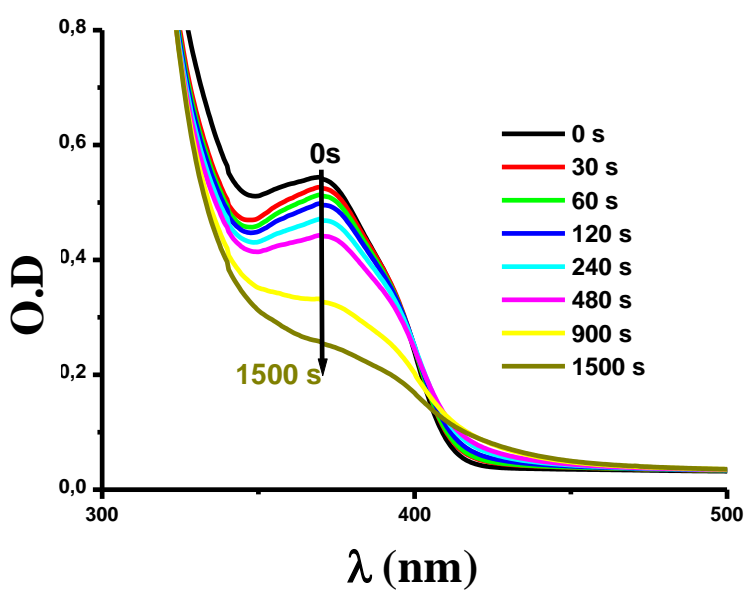

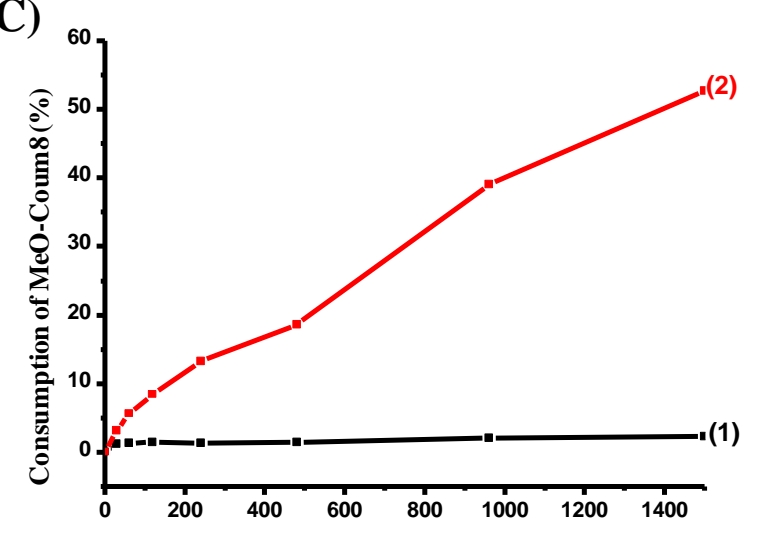

Time (s)

Figure 6: Steady state photolysis experiments of MeO-Coum8 in ACN: (A) alone, (B) with Iod $\left(10^{-2}\right.$ M). (C) Consumption (\%) of MeO-Coum8 vs. Irradiation time (s) : (1) alone, and (2) with Iod.

\subsection{Excited state reactivity and redox behaviour}

Emission spectra and fluorescence quenching experiments in $\mathrm{ACN}$ for one of the $\mathrm{KCs}$ (MeO-Coum8) are reported in Figure 7. First of all, singlet excited state energy $\left(\mathrm{E}_{\mathrm{S} 1}\right)$ could be calculated from the crossing point of the absorption and emission spectra (See Figure 7A) $\left(E_{\mathrm{S} 1}=3.05 \mathrm{eV}\right)$. A decrease of the emission intensity for MeO-Coum8 was observed by addition of Iod, EDB and NPG clearly showing an interaction between ${ }^{1} \mathrm{MeO}-\mathrm{Coum} 8$ and Iod 
(EDB or NPG). The decrease in intensity in the presence of NPG is very fast compared to that obtained in the presence of Iod or EDB. This result is in agreement with the FRP results which show a high reactivity of $\mathrm{MeO}-\mathrm{Coum} 8$ with $\mathrm{NPG}(\mathrm{FC}=83 \%)$ compared to that obtained with $\mathrm{EDB}(\mathrm{FC}=60 \%)$ and $\operatorname{Iod}(\mathrm{FC}=60 \%)$. The Stern-Volmer coefficient (Ksv) was determined in the aim to compare the KCs reactivity with different additives (Iod, EDB and NPG). Thus, when Ksv is higher, the interaction between $\mathrm{KC}$ and the additives is higher, then the electron transfer quantum yields $(\phi)$ (calculated from the eq.2) will be higher, for example MeO-Coum8 is very fast quenched with NPG compared to MeO-Coum9 so Ksv and $\phi$ of 8 $(\mathrm{Ksv}=337 \phi=0.93)$ are higher compared to $9(\mathrm{Ksv}=10, \phi=0.57)($ See Table 3$)$.

$$
\phi_{\mathrm{S} 1}=\mathrm{K}_{\mathrm{Sv}}[\mathrm{Iod}] /\left(1+\mathrm{K}_{\mathrm{Sv}}[\mathrm{Iod}]\right) \quad \text { eq. } 2
$$
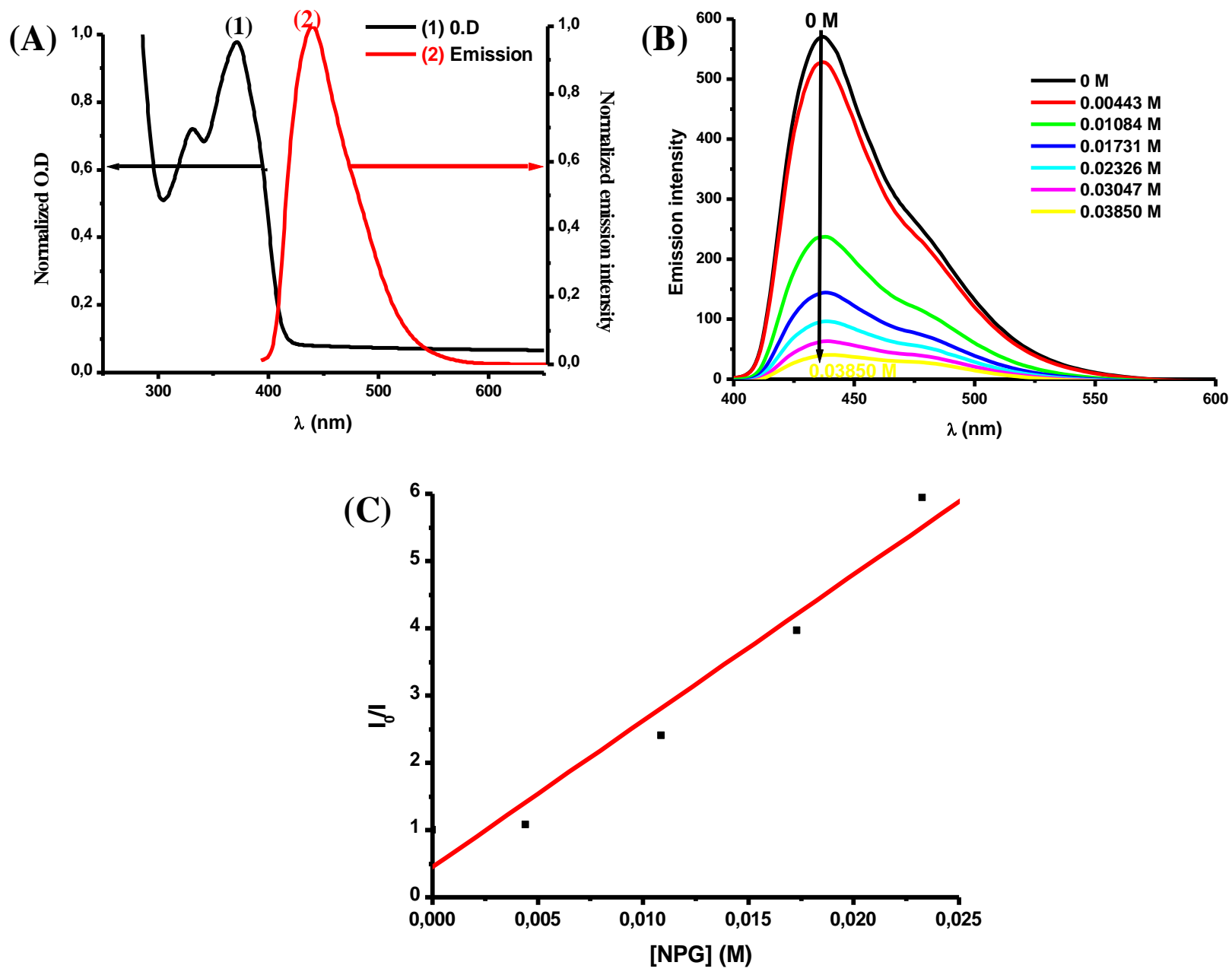

Figure 7 : (A) $\mathrm{E}_{\mathrm{S} 1}$ determination of $\mathrm{MeO}-\mathrm{Coum} 8$ in $\mathrm{ACN}$, (B) Fluorescence quenching of MeOCoum8 by NPG in ACN, (C) Stern-Volmer coefficient determination of MeO-Coum8.

Cyclic voltammetry was carried out in $\mathrm{ACN}$ to calculate the free energy change $(\Delta \mathrm{G})$ for the electron transfer between Keto-Coumarins and Iod or NPG, which is a very important 
parameter to evaluate the reaction spontaneity of FRP. $\Delta \mathrm{G}$ is calculated from $\mathrm{E}_{\mathrm{S} 1}$ and the electrochemical properties ( $\mathrm{E}_{\mathrm{ox}}$ and $\mathrm{E}_{\mathrm{red}}$ ) (using eq. 1), for example $\Delta \mathrm{G}_{\mathrm{S} 1(\mathrm{PI} / \mathrm{NPG})}=-0.19 \mathrm{eV}$ for MeO-Coum1 vs. $-0.53 \mathrm{eV}$ for $\mathrm{MeO}-\mathrm{Coum} 8$ which is more reactive in the FRP process $(\mathrm{FC}=$ $43 \%$ vs. $83 \%$ for $\mathrm{MeO}-\mathrm{Coum} 1$ and 8 respectively). All these data are summarized in Table 3 .

Tableau 3: Parameters characterizing the chemical mechanisms associated with ${ }^{1}$ Keto-Coum/Iod (EDB or NPG) interaction in acetonitrile. For Iod and NPG, a reduction and oxidation potential of -0.7 and $1.03 \mathrm{eV}$ were used respectively for the $\Delta \mathrm{Get}$ calculation.

\begin{tabular}{|c|c|c|c|c|c|c|c|c|c|c|c|}
\hline & $\begin{array}{c}E_{\text {ox }} \\
(\mathbf{e V})\end{array}$ & $\begin{array}{l}E_{\text {red }} \\
(\mathrm{eV})\end{array}$ & $\begin{array}{l}E_{s 1} \\
(e V)\end{array}$ & $\begin{array}{c}\Delta \mathbf{G}_{\mathrm{S} 1} \\
(\mathbf{P I} / \mathbf{N P G}) \\
(\mathrm{eV})\end{array}$ & $\begin{array}{c}\Delta \mathbf{G}_{\mathrm{S1}} \\
(\mathrm{PI} / \mathrm{Iod}) \\
(\mathrm{eV})\end{array}$ & $\begin{array}{c}\mathbf{K}_{\mathrm{SV}} \\
\left(\mathbf{M}^{-1}\right) \\
(\mathrm{MeO}- \\
\text { Coum/Iod) } \\
\end{array}$ & $\begin{array}{c}\mathbf{K}_{\mathrm{SV}} \\
\left(\mathbf{M}^{-1}\right) \\
(\mathrm{MeO}- \\
\text { Coum/EDB }) \\
\end{array}$ & $\begin{array}{c}\mathbf{K}_{\mathrm{SV}} \\
\left(\mathbf{M}^{-1}\right) \\
(\mathrm{MeO}- \\
\text { Coum/NPG) } \\
\end{array}$ & $\begin{array}{c}\Phi_{\text {et }} \\
\text { (MeO- } \\
\text { Coum/Iod) }\end{array}$ & $\begin{array}{c}\Phi_{\text {et }} \\
(\mathrm{MeO}- \\
\text { Coum/EDB })\end{array}$ & $\begin{array}{c}\Phi_{\text {et }} \\
(\mathrm{MeO}- \\
\text { Coum/NPG) }\end{array}$ \\
\hline MeO Coum-1 & - & -2.1 & 3.32 & -0.19 & - & 11 & 5 & 71 & 0.26 & 0.38 & 0.8 \\
\hline MeO Coum-2 & - & -1.38 & 3.20 & -0.79 & - & 5.8 & 10.7 & 77 & 0.26 & 0.51 & 0.84 \\
\hline MeO Coum-3 & - & -1.77 & 3.24 & -0.44 & - & - & 28 & 120 & - & 0.7 & 0.88 \\
\hline MeO Coum-4 & - & -1.82 & 3.23 & -0.38 & - & 14 & 45 & 123 & 0.46 & 0.6 & 0.83 \\
\hline MeO Coum-5 & - & -1.37 & - & - & - & - & - & - & - & - & - \\
\hline MeO Coum-6 & - & -1.38 & 3.08 & -0.67 & - & - & 12 & 22 & - & 0.43 & 0.64 \\
\hline MeO Coum-7 & - & -1.22 & - & - & - & - & - & - & - & - & - \\
\hline MeO Coum-8 & 0.41 & -1.52 & 3.05 & -0.5 & -1.94 & 16.5 & 116 & 217 & 0.49 & 0.77 & 0.84 \\
\hline MeO Coum-9 & 1.11 & -1.62 & 2.72 & -0.07 & -0.91 & 8 & 4.32 & 9.8 & 0.39 & 0.51 & 0.57 \\
\hline MeO Coum-10 & 0.72 & -0.7 & 2.61 & -0.88 & -1.19 & 1013 & - & 735 & 0.91 & - & 0.9 \\
\hline
\end{tabular}

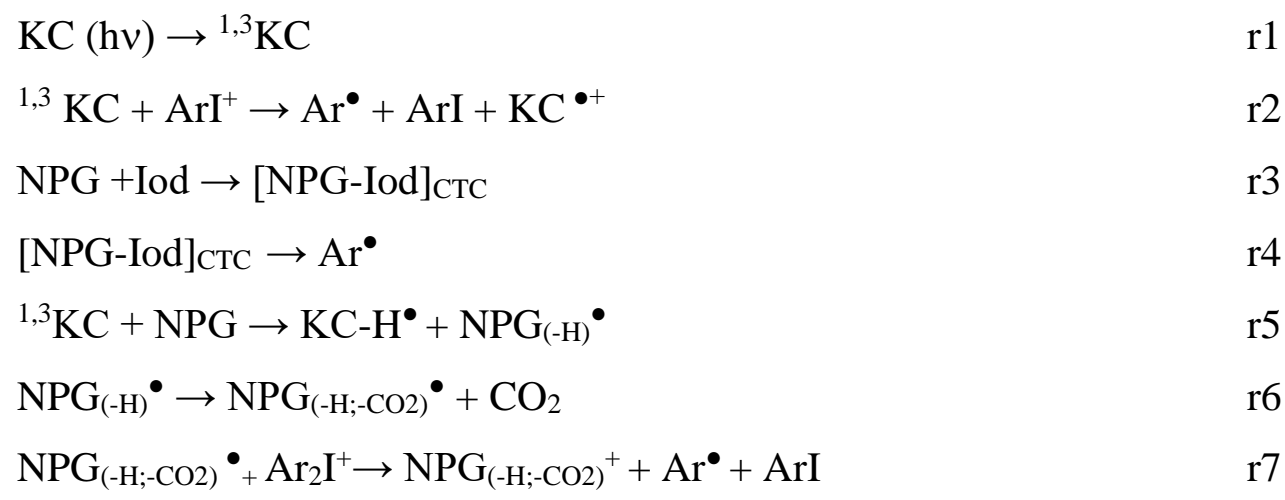

Scheme 3. Proposed chemical mechanisms 
(A)

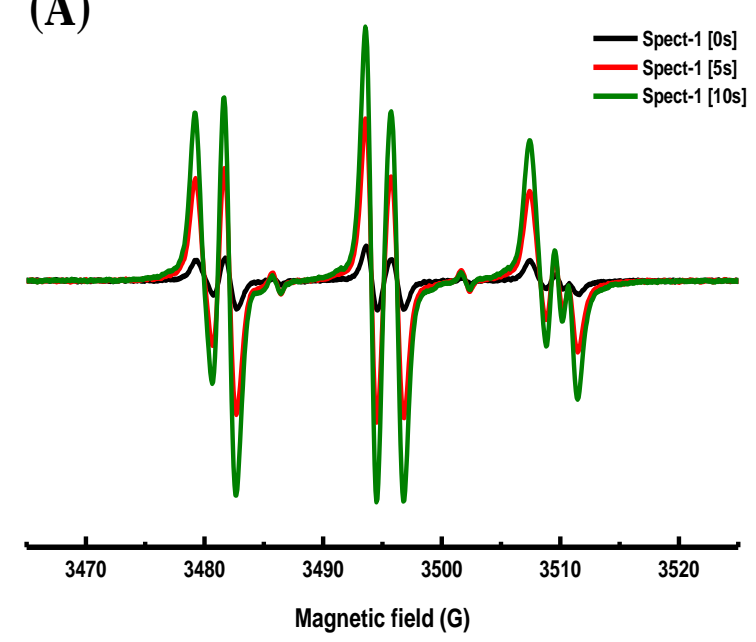

(B)

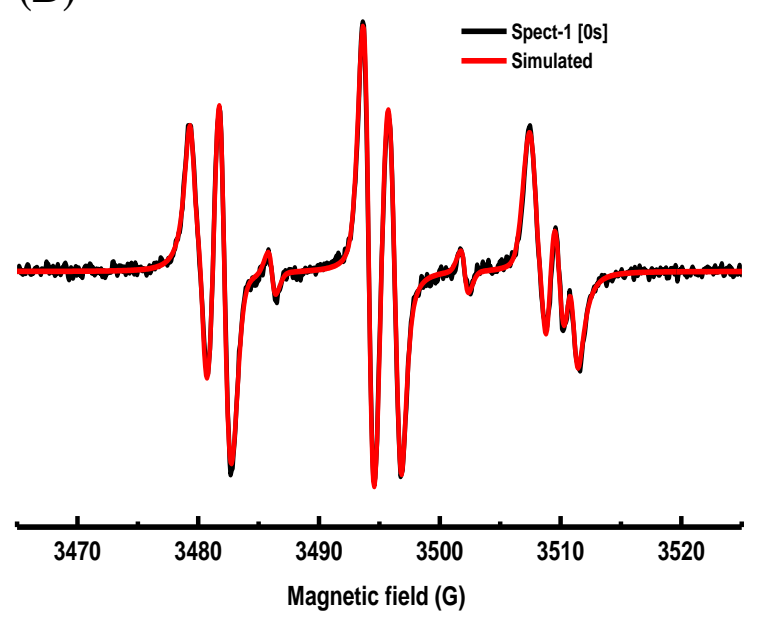

Figure 8: ESR-spin trapping experiments for the ESR spectra obtained using $\mathrm{PBN}=5.10^{-2} \mathrm{M}$ (as spin trap agent); Iodonium salt $=10^{-2} \mathrm{M}$; and $\mathrm{MeO}$-Coum8 $=10^{-2} \mathrm{M}$ in tert-butylbenzene under $\mathrm{N}_{2}$. (A) MeO-Coum8 /Iod with different irradiation time ( $0 \mathrm{~s}, 5 \mathrm{~s}$ and $10 \mathrm{~s}$ ); (B) MeO-Coum8 /Iod Irradiation time $=10 \mathrm{~s}$ experimental (black) and simulated (red) spectra.

A global mechanism can be proposed to explain the FRP results based on the different characterization techniques (Steady state photolysis, fluorescence quenching, cyclic voltammetry and ESR spectroscopy). Firstly, the $\mathrm{KC}$ is promoted in its excited state when the dye absorbs a suitable light energy. Since KC is a type II PI, KC cannot give reactive species alone, but reacts with other additives (Iod, EDB or NPG). The photoinitiating systems will be able to generate initiating radicals capable to initiate the FRP (r1-r2). The obtained radicals are certainly the aryl radicals which were detected by ESR as PBN/Ar` adducts in the irradiated solutions of Keto-Coum8/Iod. Hyperfine coupling constants (hfc) for the PBN spin adducts could be determined: $\mathrm{a}_{\mathrm{N}}=14.5 \mathrm{G}$; $\mathrm{a}_{\mathrm{H}}=2.4 \mathrm{G}$ (See Figure 8). Addition of a third additive (e.g. NPG) in the photosensitive formulation resulted in a very high performance of FRP profile. This can be explained by the more efficient generation of radicals due to the formation of a charge transfer complex between Iod salt and NPG [Iod-NPG] $]_{\text {CTC }}$ which generates reactive species (r3-r4). NPG can also react with the excited state of $\mathrm{KC}$ by a hydrogen transfer process from amine to $\mathrm{KC}$ (r4-r5) which generates two new type of radicals (Keto-Coum-H*, $\mathrm{NPG}_{(-\mathrm{H})}{ }^{\bullet}$ ). This reaction explains the high performance of the FRP of acrylate functions using Keto-Coum/NPG as PISs. By decarboxylation of $\mathrm{NPG}_{(-\mathrm{H})}{ }^{\bullet}$, a new radical $\left.\left(\mathrm{NPG}_{(-\mathrm{H} ;-\mathrm{CO} 2)}\right)^{\bullet}\right)$ is generated which can react with Iod to generate also aryl radical $\left(\mathrm{Ar}^{\bullet}\right)$ (r6-r7). 


\section{Conclusion}

In this research, ten new organic compounds based on Keto-Coumarin derivatives have been synthesized and proposed as new photoinitiating systems PISs able to initiate the FRP of acrylate functions using TMPTA or TA as benchmark acrylic resins under mild irradiation conditions. The FRP results were discussed and explained by a proposed global mechanism using different characterization techniques such as: steady state photolysis, fluorescence quenching, cyclic voltammetry and ESR experiments. These KCs have been tested in direct laser write and 3D printing as well as in the synthesis of thick glass fiber photocomposites. The different photoinitiating systems showed a very high efficiency. Development of new high-performance PISs capable to be activated at longer wavelengths (e.g. Near-Infrared) for a better light penetration into thick samples remains a great challenge and it deserves to be investigated in the future with coumarins, after modification by chemical engineering. 


\section{Reference}

1. Fouassier, J.-P.; Lalevée, J. Photoinitiators for Polymer Synthesis, Scope, Reactivity, and Efficiency; Wiley-VCH Verlag, Weinheim, 2012.

2. Fouassier, J.-P. Photoinitiator, Photopolymerization and Photo-curing: Fundamentals and Applications; Gardner Publications: New York, 1995.

3. Dietliker, K.A. Compilation of Photoinitiators Commercially Available for UV Today; Edinbergh. Sita Technology Ltd.: London, 2002.

4. Davidson, S. Exploring the Science, Technology and Application of UV and EB Curing, Sita Technology Ltd, London, 1999.

5. J.V.Crivello, K.Dietliker, G.Bradley,Photoinitiators for FreeRadical Cationic \& Anionic Photopolymerisation; John Wiley \&Sons: Chichester, U.K.,1999.

6. D. C. Neckers, W. Jager,SITA Technology Limited Chemistry \&Technology for UV \& EB Formulation for Coatings, Inks \&Paints, Photoinitiation for Polymerization: UV \& EB at the Millenium; Wiley: Chichester,1999.

7. R. R. Moraes, A. L. Faria-e-Silva, F. A. Ogliari, L. Correr-Sobrinho, F. F. Demarco, E. Piva,Acta Biomater.2009,5, 2095.

8. W. M. Palin, J. G. Leprince, M. A. Hadis,Dent. Mater.2018,34, 695.

9. Garra, P; Dietlin, C; Morlet-Savary, F; Dumur, F; Gigmes, D; Fouassier, J-P; Lalevée. Photopolymerization processes of thick films and in shadow areas: a review for the access to composites J. Polym. Chem.2017, 8, 7088.

10. Garra, P; Bonardi, A.-H; Baralle, A; Al Mousawi, A; Bonardi, F; Dietlin, C; Morlet-Savary, F; Fouassier, J-P; Lalevée, J. Monitoring photopolymerization reactions through thermal imaging: A unique tool for the real-time follow-up of thick samples, 3D printing, and composites Polym.Sci. Part A: Polym. Chem. 2018, 56, 889.

11. J. Lalevee, J.-P. Fouassier, Photopolymerisation Initiating Sys-tems, The Royal Society of Chemistry, London,2018.

12. Dietlin, C; Schweizer, S; Xiao, P; Zhang, J; Morlet-savary, F; Graff, B; Fouassier, J-P and Lalevée, J. Photopolymerization upon LEDs: new photoinitiating systems and strategies Polym. Chem., 2015, 6, 3895-3912

13. J. P. Fouassier,Photoinitiation, Photopolymerization,Photocuring, Hanser, Münich, 1995.

14. M. Schmitt,RSC Adv., 2015,5, 67284-67298.

15. M. Schmitt and J. Lalevée,Colloids Surf., A, 2017,532, 189-194.

16. Fouassier, J.-P.; Lalevée, J. Recent Advances in Photoinduced Polymerization Reactions under 400-700 nm Light. Photochem. 2014, 42, 215-232.

17. Dumur, F.; Gigmes, D.; Fouassier, J.-P.; Lalevée, J. Organic Electronics: An El Dorado in the Quest of New Photocatalysts for Polymerization Reactions. Acc. Chem. Res. 2016, 49, 1980-1989.

18. Zivic, N.; Bouzrati-Zerelli, M.; Kermagoret, A.; Dumur, F.; Fouassier, J.-P.; Gigmes, D.; Lalevée, J. Photocatalysts in Polymerization Reactions. ChemCatChem 2016, 8, 1617-1631.

19. Abdallah, M; Dumur, F; Hijazi, A; Rodeghiero, G; Gualandi, A; Cozzi, P-G ; Lalevée, J. Ketocoumarin scaffold for photoinitiators for 3D printingand photocomposites. J Polym. Sci., 2020, 58, 1115-1129. 
20. Pramanik,A; Haldar, D. Packing-induced solid-state fluorescence and thermochromic behavior of peptidic luminophores, RSC Adv., 2017, 7, 389-395

21. He,X; Shang, Y; Zhou,Y; Yu, Z; Han, G; Jin, W; Chen, J-O. Synthesis of coumarin-3-carboxylic esters via $\mathrm{FeCl}_{3}$-catalyzed multicomponent reaction of salicylaldehydes, Meldrum's acid and alcohols, Tetrahedron 71 (2015) 863-868

22. Yu, H; Hou, Z; Tian, Y; Mou, Y; Guo, C.Design, synthesis, cytotoxicity and mechanism of novel dihydroartemisinin-coumarin hybrids as potential anti-cancer agents, European Journal of Medicinal Chemistry 151 (2018) 434-449

23. Nahra, F; Macé, Y; Boreux, A; Billard, F; Riant, O. Versatile $\mathrm{Cu}^{\mathrm{I} / \mathrm{Pd}^{0}}$ Dual Catalysis for the Synthesis of Quaternary $\alpha$-Allylated Carbonyl Compounds: Development, Mechanistic Investigations and Scope, Chem. Eur. J. 2014, 20, 10970-10981

24. Yavari, I; Djahaniani, H; Nasiri, F. Synthesis of coumarines and $4 H$-chromenes through the reaction of tert-butyl isocyanide and dialkyl acetylenedicarboxylates in presence of 2hydroxybenzaldehydes, Synthesis 2004, 5, 679-682

25. Valizadeh, H; Gholipur, H; Shockravi, A. Microwave assisted synthesis of coumarins via potassium carbonate catalyzed knoevenagel condensation in 1-n-butyl-3-methylimidazolium bromide ionic liquid, J. Heterocycl. Chem., 2007, 44, 867-870

26. Qin, J-C; Yang, Z-Y; Wang, G-Q; Li, C-R. FRET-based rhodamine-coumarin conjugate as a $\mathrm{Fe}^{3+}$ selective ratiometric fluorescent sensor in aqueous media, Tetrahedron Lett. 2015, 56, 5024-5029

27. Havlik, M; Talianova, V; Kaplanek, R; Brıza, T; Dolensky, B; Kralova, J; Martasek, P; Kral, V. Versatile fluorophores for bioimaging applications: $\pi$-expanded naphthalimide derivatives with skeletal and appendage diversity, Chem. Commun., 2019, 55, 2696-2699

28. Wang, X.; Bai, X.; Su, D.; Zhang, Y.; Li, P.; Lu, S.; Gong, Y.; Zhang, W.; Tang, B. Simultaneous Fluorescence Imaging Reveals N-Methyl-D-aspartic Acid Receptor Dependent $\mathrm{Zn}^{2+} / \mathrm{H}^{+}$Flux in the Brains of Mice with Depression, Anal. Chem. 2020, 92, 4101-4107.

29. Rehm, D.; Weller, A. Kinetics of Fluorescence Quenching by Electron and H-Atom Transfer. Isr. J. Chem. 1970, 8, 259-271.

30. Foresman, J.B.; Frisch, A. Exploring Chemistry with Electronic Structure Methods, second ed., Gaussian Inc., Pittsburgh, PA, 1996.

31. M.J. Frisch, G.W. Trucks, H.B. Schlegel, G.E. Scuseria, M.A. Robb, J.R. Cheeseman, V.G. Zakrzewski, J.A. Montgomery, J.R.E. Stratmann, J.C. Burant, S. Dapprich, J.M. Millam, A.D. Daniels, K.N. Kudin, M.C. Strain, O. Farkas, J. Tomasi, V. Barone, M. Cossi, R. Cammi, B. Mennucci, C. Pomelli, C. Adamo, S. Clifford, J. Ochterski, G.A. Petersson, P.Y. Ayala, Q. Cui, K. Morokuma, P. Salvador, J.J. Dannenberg, D.K. Malick, A.D. Rabuck, K. Raghavachari, J.B. Foresman, J. Cioslowski, J.V. Ortiz, A.G. Baboul, B.B. Stefanov, G. Liu, A. Liashenko, P. Piskorz, I. Komaromi, R. Gomperts, R.L. Martin, D.J. Fox, T. Keith, M.A. Al-Laham, C.Y. Peng, A. Nanayakkara, M. Challacombe, P.M.W. Gill, B. Johnson, W. Chen, M. Wong, J.L. Andres, C. Gonzalez, M. Head-Gordon, E.S. Replogle, J.A. Pople, Gaussian 03, Revision B-2, Gaussian Inc., Pittsburgh, PA, 2003. 
32. Zhang, J.; Dumur, F.; Xiao, P.; Graff, B.; Bardelang, D.; Gigmes, D.; Fouassier, J.-P.; Lalevée, J. Structure Design of Naphthalimide Derivatives: Toward Versatile Photoinitiators for Near-UV/Visible LEDs, 3D Printing, and Water-Soluble Photoinitiating Systems. Macromolecules 2015, 48, 20542063.

\section{Acknowledgements}

The Lebanese group would like to thank "The Association of Specialization and Scientific Guidance" (Beirut, Lebanon) for funding and supporting this scientific work. 

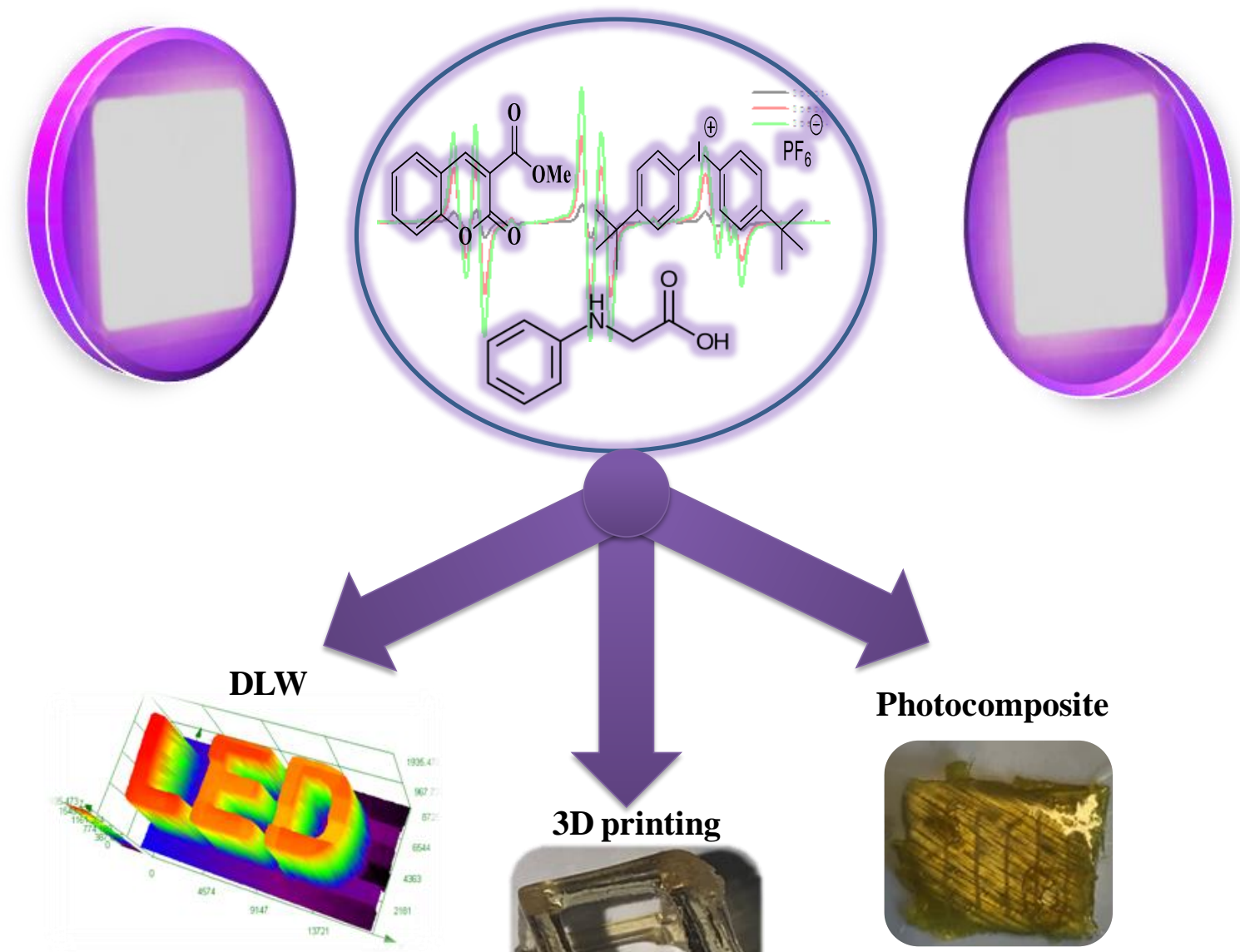

Photocomposite

\section{D printing}

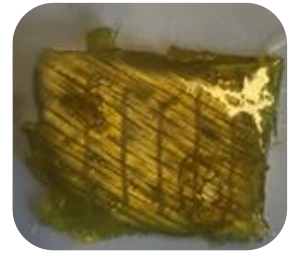

